\title{
PROTECCIÓN DE LAS PERSONAS MIGRANTES INDOCUMENTADAS EN ESPAÑA CON ARREGLO AL DERECHO INTERNACIONAL Y EUROPEO DE LOS DERECHOS HUMANOS
}

\author{
PROTECTION OF UNDOCUMENTED MIGRANT PERSONS IN \\ SPAIN UNDER INTERNATIONAL AND EUROPEAN HUMAN \\ RIGHTS LAW
}

\author{
Dorothy Estrada TANCK \\ Doctora en Derecho por el Instituto Universitario Europeo de Florencia, Italia \\ Profesora de Derecho Internacional Público y RR. II. \\ Universidad de Murcia
}

Recibido: 31.05.2017 / Aceptado: 09.06.2017

DOI: https://doi.org/10.20318/cdt.2017.3873

\begin{abstract}
Resumen: Este artículo trata sobre el régimen jurídico de protección de las personas migrantes indocumentadas en España, realizando una cartografía integral de los instrumentos internacionales y europeos de derechos humanos que les resultan aplicables y contrastando dicho marco jurídico con la normatividad y la práctica en el país. El trabajo identifica de modo temático y casuístico los riesgos y vulnerabilidades que enfrentan las personas migrantes en España y en la UE, y los examina de modo crítico y a la vez propositivo a la luz de los principios de igualdad y no-discriminación, la jurisprudencia de los órganos de NU y del TEDH, así como de las herramientas protectoras del propio orden jurídico español.

Palabras clave: migrantes, derecho internacional de los derechos humanos, derecho europeo de los derechos humanos, migrantes en España, vulnerabilidad.
\end{abstract}

Abstract: This article addresses the legal regime of the protection of undocumented migrants in Spain, integrally mapping the international and European human rights instruments that are applicable to them and contrasting such legal framework with the normativity and practice in the country. It identifies in a thematic and casuistic way, the risks and vulnerabilities confronted by undocumented migrants in Spain and the EU, and examines them critically and at the same time constructively under the light of the principles of equality and non-discrimination, the jurisprudence of UN bodies and the ECHR, as well as the protective tools provided by the Spanish legal system itself.

Keywords: migrants, international human rights law, European human rights law, migrants in Spain, vulnerability.

Sumario: I. Introducción. II. Marco jurídico internacional sobre los derechos humanos de las personas migrantes: el sistema de Naciones Unidas. 1. Instrumentos de derechos humanos aplicables a las personas migrantes. A) Principales tratados internacionales, órganos de supervisión e interpretaciones. B) Relator de Naciones Unidas, OACNUDH y Declaración de Nueva York. C. Convención Internacional sobre la Protección de los Derechos de Todos los Trabajadores Migratorios y de sus Familiares. III. El sistema europeo de derechos humanos: Consejo de Europa y UE. 1. Consejo de Europa. 2. Unión Europea. IV. Marco jurídico y práctica en España a la luz de los derechos humanos. 1. Retos generales, igualdad y no-discriminación. 2. Derecho humano a la salud y otros derechos económicos, sociales y culturales (DESC). 3. Riesgo y vulnerabilidad agravada para mujeres y niñas migrantes. 4. Violaciones en frontera y devoluciones 'en caliente'. V. Reflexiones finales. 


\section{Introducción}

1. El análisis de la migración como fenómeno típicamente transnacional invita a una reflexión más profunda acerca de la relación que guarda con ella el sistema jurídico internacional como una de las herramientas principales de su normativización. El Derecho Internacional Público ha abordado la protección de las personas migrantes mediante distintos instrumentos, particularmente a través del Derecho Internacional de los Derechos Humanos. Asimismo, el Derecho Europeo de los Derechos Humanos -tradicionalmente entendido como aquél que deriva del Consejo de Europa y el Convenio Europeo de Derechos Humanos, pero integrado también por las normas en materia de derechos humanos de la Unión Europea (UE)-, juega un importante papel en la protección de los derechos de las personas que migran de su país de origen o residencia.

2. Este marco jurídico protector parecería en ocasiones contrastar con la realidad empírica. En efecto, las personas migrantes, en especial las personas migrantes indocumentadas, así como otros migrantes como las personas solicitantes de asilo y las refugiadas, enfrentan diariamente situaciones de vulnerabilidad, inseguridad humana e incluso indefensión en distintas partes del mundo, incluida España. Esta condición es marcadamente patente en el caso de las mujeres, niñas y niños. ${ }^{1}$

3. Los movimientos migratorios actuales, si bien no son nuevos, sí demuestran un crecimiento exponencial de los flujos desde Syria, Iraq y Afghanistán, mayoritariamente a Turquía, Jordania y Líbano, y en menor medida, a Europa. La terrible tragedia de miles de personas que han fallecido en el mar tratando de llegar a las costas europeas del Mediterráneo ha crecido dramáticamente desde 2015 a los primeros meses de 2017, con el resultado de más de 5,000 muertes registradas sólo en $2016 .{ }^{2}$

4. En el presente artículo se argumenta que los riesgos severos que confrontan las personas migrantes indocumentadas -varias de ellas potenciales refugiadas-, presentan retos jurídicos en términos de la verdadera universalidad de los derechos humanos cuando ésta se analiza a la luz del estatus migratorio irregular. Su situación abre también preguntas desde la perspectiva práctica, habida cuenta de que la falta de protección experimentada por las personas migrantes indocumentadas se ha agravado con la crisis económica de los últimos años en Europa y en España, el aumento de los flujos de movilidad humana, la rigidización de la normatividad migratoria y la criminalización de las acciones de ayuda a las personas migrantes. ${ }^{3}$

5. Frente a estas realidades recientes, el Alto Comisionado de Naciones Unidas para los Derechos Humanos, ha recordado que "el derecho internacional de los derechos humanos requiere que los Estados protejan los derechos humanos de todos sin discriminación" y ha enfatizado que en vista de las realidades migratorias contemporáneas "considera particularmente pertinente que se garantice que estas protecciones de derechos humanos sean efectivas y accesibles a todas las personas migrantes, independientemente de su estatus migratorio". ${ }^{4}$

\footnotetext{
1 Véase, e.g, Amnistía Internacional, Informe sobre los Derechos Humanos en España, 2016, disponible en https://www. es.amnesty.org/en-que-estamos/espana/\#c30834; RELATORA EsPeCIAL DE NU sobre ViolenCIA CONTRA LAS Mujeres, Informe presentado al Consejo de Derechos Humanos de NU (UNGA A/66/215), 2011; así como, de reciente publicación, REPRESENTANTE Especial del Secretario General del Consejo de Europa sobre Personas Migrantes, Tomáš Boček, Informe temático sobre niñas y niños migrantes y refugiados, marzo de 2017.

2 Organización Internacional de las Migraciones (OIM), ‘Missing Migrants Project, Migrant Fatalities Worldwide', actualizado a abril de 2017, disponible en http://missingmigrants.iom.int/latest-global-figures, Y T. BRIAN,Y F.LACZKO (editores), Fatal Journeys: Tracking Lives Lost during Migration, International Organization for Migration, 2014.

3 Véase, e.g., V. Mitsilegas, The Criminalisation of Migration in Europe: Challenges for Human Rights and the Rule of Law, Springer, 2015. Sobre el incremento del control fronterizo de la UE, véase, por ejemplo, 'Cronología - Respuestas a las presiones migratorias', actualizada a febrero de 2017, en http://www.consilium.europa.eu/es/policies/migratory-pressures/ history-migratory-pressures/

4 OACNUDH, 'Intervener Brief filed by the United Nations High Commissioner for Human Rights, pursuant to leave granted by the Court on 9 October 2015', en el caso del TEDH, N.D. y N.T. v España, $\mathrm{N}^{\circ}$ 8675/15 y 8697/15, Decisión de admisibilidad, 30 de julio de 2015, párr. 2 (traducción propia).
} 
6. Sobre la base del marco jurídico internacional y europeo existente, y a la luz de los riesgos que enfrentan las personas migrantes indocumentadas, el presente artículo se plantea que el Derecho en España -incluyendo disposiciones normativas e interpretaciones judiciales-, puede y debe enriquecerse a través del Derecho Internacional y Europeo de los Derechos Humanos, para hacer frente a las amenazas nacionales y transnacionales que afectan los derechos humanos de las personas migrantes indocumentadas.

7. En ese contexto, específicamente por "persona migrante indocumentada", este artículo entiende las personas sin un permiso de residencia que les autorice a permanecer regularmente o trabajar en el país de destino. Es posible que no hayan tenido éxito en el procedimiento de asilo, hayan sobrepasado el tiempo de estancia permitido por sus visas o que hayan entrado irregularmente al país de destino. Las rutas para llegar a ser una persona migrante indocumentada son complejas y, en ocasiones, el resultado de políticas arbitrarias y procedimientos sobre los cuales la persona migrante tiene poco o ningún control.

8. Una vez definido el sujeto de atención del presente estudio, este artículo analizará algunos aspectos destacados de los principales regímenes normativos y judiciales del Derecho Internacional y Europeo de los Derechos Humanos que afecta a las personas migrantes indocumentadas. En primer lugar, se evalúa el marco jurídico formal de tratados internacionales, así como los desarrollos normativos e interpretativos, a nivel de Naciones Unidas y posteriormente aquéllos del ámbito regional del Sistema Europeo de Derechos Humanos y el Derecho de la UE. Sobre esa base normativa, se examinará después el marco jurídico y la práctica en España a la luz de los parámetros internacionales de derechos humanos, sistematizando y agrupando algunos de los principales problemas detectados por tema de análisis y el tipo de preguntas específicas que cada uno provoca.

9. Por último, se apuntarán una serie de reflexiones y de conclusiones derivadas del análisis conceptual, casuístico y práctico presentado. En ellas se sugiere que debe trabajarse de forma más activa en la relación Derecho Internacional de los Derechos Humanos-Sistema Europeo de Derechos Humanos con el Derecho Español como modelo de protección más efectiva de los derechos humanos de las personas migrantes, especialmente aquellas en condición de mayor vulnerabilidad.

\section{Marco jurídico internacional sobre los derechos humanos de las personas migrantes: el sistema de Naciones Unidas}

10. Como punto de partida, recordemos que sobre la base de los principios de igualdad y no discriminación, comunes a todo el Derecho Internacional Público, el marco jurídico de las Naciones Unidas ha reafirmado repetidamente los derechos humanos de todas las personas, entre las cuales como es evidente se incluyen las personas migrantes, y la prohibición de la discriminación basada en distintas casusas, entre ellas el origen nacional o social o cualquier otra condición. ${ }^{5}$

\section{Instrumentos de derechos humanos aplicables a las personas migrantes}

11. Con base en el punto de partida mencionado, la comunidad internacional de Estados (con la participación de otros actores como organizaciones no gubernamentales y partes interesadas) ha ido construyendo el Derecho Internacional de los Derechos Humanos, como una de las expresiones del Derecho Internacional Público, que contempla y protege a todas las personas migrantes, documentadas e indocumentadas de la manera que aquí se examina.

12. Debe recordarse que España es parte de los principales instrumentos internacionales de derechos humanos. En efecto, en el marco del sistema internacional de derechos humanos, puede citarse primeramente la Declaración Universal de los Derechos Humanos de 1948, aplicable a todos los seres

\footnotetext{
${ }^{5}$ Véase el fundamento general en los artículos 1(3) y 55 de la Carta de las Naciones Unidas (1945) y la mención específica en el artículo 2 de la Declaración Universal de Derechos Humanos (1948).
} 
humanos, independientemente de su condición migratoria, y aceptada hoy en día como costumbre internacional, es decir, como una de las fuentes primarias del Derecho Internacional Público, con base en el artículo 38. 1a) del Estatuto de la Corte Internacional de Justicia.

13. Específicamente el artículo 2.1 de la DUDH afirma que Toda persona tiene todos los derechos y libertades proclamados en esta Declaración, sin distinción alguna de raza, color, sexo, idioma, religión, opinión política o de cualquier otra índole, origen nacional o social, posición económica, nacimiento o cualquier otra condición.

\section{A) Principales tratados internacionales, órganos de supervisión e interpretaciones}

14. Bajo el 'paraguas normativo' de la DUDH, a través de los años se han ido adoptando una serie de tratados internacionales de derechos humanos que conforman una sólida estructura normativa, que concretan los derechos humanos de todas las personas, crean mecanismos jurídicos para su supervisión e interpretación y prestan atención particular a grupos específicos con necesidades diferenciadas.

15. A nivel de tratados, como otra fuente primaria del Derecho Internacional Público, España es Estado Parte de los principales tratados internacionales de derechos humanos: el Pacto Internacional de Derechos Civiles y Políticos (1966) (PIDCP); el Pacto Internacional de Derechos Económicos, Sociales y Culturales (1966) (PIDESC); la Convención sobre la Eliminación de Todas las Formas de Discriminación Racial (1965) (CERD); la Convención sobre la Eliminación de Todas las Formas de Discriminación Contra la Mujer (1979) (CEDAW, por sus siglas en inglés); la Convención contra la Tortura y Otros Tratos o Penas Crueles, Inhumanos o Degradantes (1984) (CAT, por sus siglas en inglés); la Convención sobre Derechos de la Niñez (1989) (CDN); la Convención Internacional para la Protección de Todas las Personas contra las Desapariciones Forzadas (2006) (CDF); y la Convención sobre los Derechos de las Personas con Discapacidad (2008) (CDPD), todos los cuales son directamente aplicables a todas las personas, incluyendo como queda claro del lenguaje universalista en ellos utilizado, a las personas migrantes indocumentadas, en proceso de documentarse y documentadas. ${ }^{6}$

16. Asimismo, a la vista de la situación actual de refugiados en Europa, y aunque el presente artículo no aborda a profundidad la situación particular de las personas solicitantes de asilo, es relevante tener presente que España también es parte de la Convención sobre el Estatuto de los Refugiados de 1951, y de su Protocolo de 1967. ${ }^{7}$ Ello debe mantenerse en mente en tanto que en la vida real los flujos migratorios no llegan clasificados de forma ordenada y clara como las categorías jurídicas creadas a estos efectos: existen personas que en un primer momento llegan al país receptor de forma indocumentada y no sólo en la frontera sino también en el territorio y ya pasado un tiempo o desde su entrada al mismo, solicitan la protección internacional que comprende las dos figuras de refugio y la protección subsidiaria; y al contrario, algunas de las personas solicitantes de asilo a lo largo de su proceso de solicitud, caen en situaciones de irregularidad administrativa/migratoria y por tanto entran en el terreno de las personas migrantes indocumentadas. ${ }^{8}$

17. Debe tenerse presente que cada uno de los tratados internacionales de derechos humanos mencionados ha establecido un Comité de expertos encargado de supervisar la aplicación del tratado por los Estados Partes. Algunos de los tratados se complementan con protocolos facultativos relativos

${ }^{6}$ El restante tratado principal de derechos humanos, la Convención Internacional sobre la Protección de los Derechos de Todos los Trabajadores Migratorios y de sus Familiares (CTM) y la posición de España respecto del mismo, se abordará en el siguiente apartado.

7 Dicha normativa internacional se ve reflejada en la Ley 12/2009, de 30 de octubre, reguladora del derecho de asilo y de la protección subsidiaria. BOE, núm. 263, de 31 de octubre de 2009. Para un análisis más completo de las implicaciones de esta pertenencia, véase, e.g., M.T. GIL-BAzo, 'Refugee Status, Subsidiary Protection, and the Right to be Granted Asylum under EC Law', Research Paper No 136, Refugee Studies Centre, Oxford University, UK-UNHCHR Policy Development and Evaluation Service, November 2006.

8 Véase datos en Ministerio de Empleo y Seguridad Social, Perspectiva Jurídica 2016, Comisión Jurídica y de Asuntos Internacionales, Informe Anual 2016. 
a preocupaciones específicas. Estos órganos de supervisión de los tratados también han confirmado reiteradamente, en particular en los últimos quince años, la aplicabilidad de todos los derechos humanos -civiles, políticos, económicos, sociales y culturales- a las personas migrantes y la prohibición de la discriminación basada en el origen nacional o en el estatus migratorio.

18. A nivel de las disposiciones e interpretaciones de dichos Comités más estrechamente relacionadas con las personas migrantes, debemos considerar el artículo 27 del PIDCP, que se refiere a las minorías étnicas, religiosas y lingüísticas (que frecuentemente integran a personas migrantes); el artículo 30 de la Convención sobre los Derechos de la Niñez y el artículo 5 de la Declaración y Programa de Acción de Viena (1993); la Declaración de NU sobre los Derechos Humanos de los Individuos que no son Nacionales del País en que Viven (1985); la Observación General No. 15 del Comité de Derechos Humanos -órgano que supervisa el cumplimiento del PIDCP-, sobre la Situación de los extranjeros de conformidad con el PIDCP (1986); la Observación General N ${ }^{\circ} 23$ también del Comité de Derechos Humanos, Los derechos de las minorías (artículo 27) (1994), que indica que los derechos del artículo 27 del Pacto también se aplican a los trabajadores migrantes; la Recomendación General No. 30 del Comité para la Eliminación de la Discriminación Racial, Discriminación contra los no ciudadanos (2004); la Observación General No. 6 del Comité de Derechos del Niño, Trato de los menores no acompañados y separados fuera de su país de origen (2005); y la Recomendación General No. 26 sobre Trabajadoras Migratorias, así como la Recomendación General No. 32 sobre las dimensiones de género del estatuto de refugiada, el asilo, la nacionalidad y la apatridia de las mujeres, ambas del Comité para la Eliminación de la Discriminación contra la Mujer (2008 y 2014, respectivamente).

19. Los distintos órganos de supervisión de tratados del sistema de Naciones Unidas, además de formular estas interpretaciones generales, han resuelto casos individuales de quejas por violaciones a los derechos contenidos en cada tratado, presentados contra los Estados Parte del tratado correspondiente, incluido España. Los distintos casos concernientes a España se estudiarán de forma temática más adelante en cada sección correspondiente del apartado referido al marco y práctica en el país.

20. Una inquietud frecuente formulada por los Estados es que la defensa de los derechos humanos de las personas migrantes indocumentadas podría restringir los poderes soberanos del Estado en materia de migración o poner en peligro la estabilidad económica y el bienestar de la población nacional. A este respecto, Ruth Rubio Marín y Cristina Rodríguez han argumentado que el propio marco de los derechos humanos ofrece los mecanismos de equilibrio suficientes para permitir el ejercicio de las facultades del Estado, mientras que al mismo tiempo promueve un estándar coherente de respeto y protección de titularidades humanas fundamentales, pilar central de las democracias constitucionales -muchas de ellas países receptores de migración-. Esta "concesión derechos humanos-soberanía" puede arrojar luz sobre las formas de enfrentar el dilema que las medidas contra la inmigración irregular sin duda representa para la idea de personalidad universal y dignidad humana. ${ }^{9}$

21. En este sentido, con base en el marco jurídico descrito, es necesario enfatizar que, al abordar los derechos de las personas migrantes, el punto de partida en el debate no es -como a menudo se pretende-, la soberanía nacional de los Estados y su capacidad para regular fronteras territoriales, sino más bien lo que el Derecho o los diferentes sistemas jurídicos, tienen que decir acerca de tales derechos y los principios que los sustentan.

\section{B) Relator de Naciones Unidas, OACNUDH y Declaración de Nueva York}

22. El Relator Especial de NU sobre Derechos Humanos de los Migrantes, François Crépeau, que analiza la situación de derechos humanos de las personas migrantes en todos los países del mundo

\footnotetext{
9 B. Rodríguez Ruiz y R. Rubio-Marín, "The constitutional status of irregular migrants: testing the boundaries of human rights protection in Spain and the United States", en M.B. Dembour y T. Kelly (eds), Are Human Rights for Migrants? Critical Reflections on the Status of Irregular Migrants in Europe and the United States, Routledge, (2011), pp. 73-98 (traducción propia). Las autoras se refieren a esta concesión o balance como el human rights-sovereignty compromise.
} 
-independientemente de la pertenencia o no de cada Estado a los tratados de derechos humanos- destacó una tendencia preocupante. El Relator hizo notar las declaraciones de algunos servidores públicos y medios de comunicación en el sentido de considerar que los inmigrantes que llegan a un Estado y no han sido invitados a venir o a entrar, de algún modo no gozan de los mismos derechos que el resto de las personas. Ello ha dado lugar a la creación de espacios de discrecionalidad administrativa basada en una especie de creencia subyacente de que existen dos tipos de derechos humanos, los de los ciudadanos y los de una categoría de segunda clase, merecidos por los no-ciudadanos. Es necesario subrayar, sin embargo, como lo aclaró el Relator, que el Derecho Internacional es firme en indicar que todos los derechos humanos existen para ser disfrutados por todos los seres humanos, con las únicas excepciones permitidas por el propio Derecho Internacional de los Derechos Humanos. ${ }^{10}$

23. Así, el paradigma universal de los principios rectores de derechos humanos sostiene que todas las personas son iguales en dignidad y derechos, y por tanto no deben ser discriminadas. Sin embargo, la universalidad de los derechos humanos parece ser puesta en duda cuando se confronta con la condición de las personas migrantes. En efecto, "a pesar de la universalidad teórica de los derechos humanos, en la realidad ciertas características como la nacionalidad o el estatus legal formal pueden afectar significativamente el alcance de los derechos que de hecho se conceden a una persona". ${ }^{11}$

24. La aplicación progresivamente severa de las restricciones de inmigración, puede dejar y de hecho deja a las personas fuera del derecho o invisibles para el derecho, y por lo tanto en una condición de vulnerabilidad. Paradójicamente, la implementación rigurosa y a menudo arbitraria del derecho administrativo en materia migratoria parece estar obstaculizando la aplicación efectiva y los fines de los derechos humanos y el derecho laboral.

25. En ese contexto, en un estudio de 2013 sobre el marco migratorio de la UE, ${ }^{12}$ y el seguimiento realizado en 2015 -en plena 'crisis' de refugiados-, el Relator de NU recomendó que la UE reconociera plenamente los factores de empuje y atracción de la migración irregular, incluida la que se realiza por mar, y la responsabilidad de la UE en la gestión y mitigación de los mismos. Al dar prioridad a los canales regulares de migración, el Relator recomendó que la UE asumiera un papel de liderazgo mundial en relación con la guerra civil siria y otras crisis humanitarias y redujera el mercado para el tráfico de personas migrantes mediante el desarrollo, en colaboración con otros Estados del Norte, de oportunidades de reasentamiento para que la UE pudiera albergar a más de un millón de personas refugiadas del mundo $\left(0,2 \%\right.$ de la población total de la UE) durante un periodo de varios años. ${ }^{13}$

26. Por su parte, reconociendo también la complejidad del respeto de los estándares de derechos humanos en situaciones de presiones migratorias en las fronteras estatales y en un mundo dividido por

${ }^{10}$ Declaraciones de F. CRÉPEAU en el "Debate sobre la gestión de las fronteras exteriores de la UE y su impacto sobre los derechos humanos de los migrantes: la experiencia italiana. Una consulta entre el Relator Especial de NU sobre los Derechos Humanos de los Migrantes, Sr. François Crepeau, la sociedad civil y el mundo académico", organizado por el Migration Policy Centre, Centro Robert Schuman de Estudios Avanzados del Instituto Universitario Europeo de Florencia (IUE), con el apoyo de Open Society Foundation, y celebrado en el IUE en Florencia, Italia, el 3 de octubre de 2012. Registro personal. Véase el comunicado de prensa "Relator Especial de NU sobre los derechos humanos de los migrantes concluye su visita al tercer país de su estudio regional sobre los derechos humanos de los migrantes en las fronteras de la Unión Europea: Italia", Roma, 8 de octubre de 2012, en http:// www.ohchr.org/EN/NewsEvents/Pages/DisplayNews.aspx?NewsID=12640\&LangID=E

11 J. McAdam, Complementary Protection in International Refugee Law, Oxford Monographs in International Law, Oxford University Press, 2007, p. 12. Véase también en este sentido M.J. AÑón (editora), La universalidad de los derechos sociales: el reto de la inmigración, Tirant lo Blanch, Valencia, España, 2004; y A. Solanes Corella, (editora), Derechos humanos, migraciones y diversidad, Tirant lo Blanch, Valencia, España, 2010.

12 Relator Especial de NU sobre Derechos Humanos de los Migrantes, F. Crépeau, 'Report on the Regional Study on the Management of the External Borders of the European Union and its Impact on the Human Rights of Migrants', A/ $\mathrm{HRC} / 23 / 46,2013$.

13 Relator Especial de NU sobre Derechos Humanos de los Migrantes, F. Crépeau, 'Banking on Mobility over a Generation: Follow-up to the Regional Study on the Management of the External Borders of the European Union and its Impact on the Human Rights of Migrants", A/HRC/29/36, 8 de mayo de 2015, párrs. 98 y 100 (traducción propia). 
jurisdicciones territoriales de Estados, los organismos de derechos humanos han realizado esfuerzos para proporcionar criterios más claros sobre cómo enfrentar tales desafíos. La Oficina del Alto Comisionado de Naciones Unidas para los Derechos Humanos (OACNUDH) emitió en 2014 los Principios y Directrices Recomendados sobre los Derechos Humanos en las Fronteras Internacionales, resultantes de consultas llevadas a cabo con una amplia gama de expertos y partes interesadas. Sobre la base de tres principios que consisten en la primacía de los derechos humanos; la no-discriminación; y la asistencia y protección contra cualquier daño, el instrumento contiene 10 directrices concretas sobre la gestión de las fronteras internacionales.

27. Los Principios reiteran, sin embargo, que el punto de partida es la afirmación de que el respeto de los derechos humanos de todos los migrantes, independientemente de su nacionalidad, situación migratoria u otras circunstancias, facilita la gobernanza efectiva de las fronteras. Bajo una óptica ética y jurídica, pero a la vez pragmática, los Principios enfatizan que

Las políticas cuyo objetivo no es la gestión de la migración sino su restricción a toda costa sólo sirven para exacerbar los riesgos a los que se exponen los migrantes y crear zonas de ilegalidad e impunidad en las fronteras; además, en última instancia, resultan ineficaces... Por lo tanto, [las] Directrices se recomiendan a los Estados y a otras partes interesadas no sólo por su obligación de hacer que los derechos humanos sean una prioridad en las medidas de gobernanza de sus fronteras, sino también porque les beneficia que así sea. ${ }^{14}$

28. Como tal, el documento reconoce las realidades empíricas del sufrimiento de las personas migrantes, le da voz y forma a las inquietudes por ellas expresadas, ${ }^{15}$ y tiene la intención de orientar la acción del Estado y adaptar la implementación de los derechos humanos a las situaciones migratorias contemporáneas, mediante lineamientos concretos.

29. Así, los Principios reiteran la perspectiva de que el Derecho Internacional Público se ha construido, entre otros factores, precisamente a través del entendimiento progresivo de la soberanía del Estado como la responsabilidad de velar por una serie de valores y condiciones de vida respecto de las personas bajo su jurisdicción, qua personas con dignidad, como una razón suficiente para el reconocimiento jurídico y el disfrute del conjunto de sus derechos. ${ }^{16}$ En ese sentido, la primera afirmación que tendría que señalarse es que los derechos humanos universales son, en principio, aplicables a todas las personas migrantes, documentadas e indocumentadas, a las personas solicitantes de asilo y refugiadas. Es decir, no se necesita "un visado o un permiso de residencia para tener derecho a los derechos humanos. Simplemente nacer es el pasaporte para acceder a la protección de los derechos humanos". ${ }^{17}$

30. Esta postura ha sido reiterada por la 'Declaración de Nueva York para los Refugiados y los Migrantes', aprobada el 19 de septiembre de 2016 tras la reunión plenaria de alto nivel de la Asamblea General de Naciones Unidas (AGNU) sobre la respuesta a los grandes desplazamientos de refugiados y migrantes. En ella, los Jefes de Estado y de Gobierno y Altos Representantes, entre ellos el de España, reafirmaron los derechos humanos de todos los refugiados y migrantes, independientemente de su condición, y se comprometieron a proteger plenamente esos derechos. ${ }^{18}$

${ }^{14}$ OACNUDH, Principios y Directrices Recomendados sobre los Derechos Humanos en las Fronteras Internacionales, OACNUDH, Ginebra, Suiza, 2014, párr. 4, pp. 2-3.

15 Sobre la importancia de dar voz a las personas migrantes en relación con las políticas que les afectan, véase F. CRÉPEAU, 'Smugglers Will Always Outwit, Outpace And Outfox The Governments', Interview with François Crépeau, United Nations Special Rapporteur on the human rights of migrants on the so-called "migration crisis" in Europe, in Sur International Journal on Human Rights, No. 23, julio de 2016, p. 03.

${ }^{16}$ En este sentido, véase A. CASSESE, International Law, Oxford, Oxford University Press, segunda edición, 2005, p. 45.

17 M. KJaerum, Director de la Agencia de Derechos Fundamentales de la UE, "La dignidad y los derechos de los migrantes irregulares", 4a Conferencia de Derechos Fundamentales, Varsovia, Polonia (21y 22 de noviembre de 2011), p. 2 (traducción propia; cursivas propias; subrayado en original). Disponible en http://fra.europa.eu/fraWebsite/attachments/MK-Speech-FRCNOV2011.pdf

${ }^{18}$ Resolución 71/1 de la Asamblea General de Naciones Unidas, párr. 5. 
31. Recordaron que "aunque el trato que se les dispensa se rige por marcos jurídicos separados, los refugiados y los migrantes tienen los mismos derechos humanos universales y libertades fundamentales", ${ }^{19}$ apunte y aclaración importante habida cuenta de algunas propuestas políticas en Europa que actualmente colocan a las personas migrantes como una especie de "ciudadanos de segunda categoría', como ya hacía notar el Relator Especial de NU sobre derechos humanos de los migrantes, Francois Crépeau. Esta concepción no se queda sólo en posiciones políticas que pudieran calificarse de extrema derecha o populistas, sino que con frecuencia se encuentran 'objetivizadas' y 'juridizadas' a través de los derechos nacionales en materia de control de fronteras y de extranjería de varios Estados, incluida España, como veremos en el presente artículo.

32. Al respecto, cabe recordar que mediante la Declaración de Nueva York los Jefes de Estado y de Gobierno y Altos Representantes se comprometieron a trabajar para concertar en 2018 un pacto mundial sobre la cuestión de las personas refugiadas y un pacto mundial para la migración 'segura, ordenada y regular'.

\section{C) Convención Internacional sobre la Protección de los Derechos de Todos los Trabajadores Mi- gratorios y de sus Familiares}

33. De toda la estructura de Naciones Unidas en materia de derechos humanos, uno de los nueve tratados internacionales fundamentales se refiere a las personas migrantes, en particular a los trabajadores migratorios y sus familiares. En efecto, la Convención Internacional sobre la Protección de los Derechos de Todos los Trabajadores Migratorios y de sus Familiares (CTM), adoptada en 1990 y en vigor desde 2003, desde el punto de partida de su nombre se refiere a los derechos de todos los trabajadores y trabajadoras migratorios, es decir, tanto documentados como indocumentados, así como a los miembros de sus familias. La CTM en la Parte IV también establece derechos adicionales específicos para las y los trabajadores migratorios documentados. ${ }^{20} \mathrm{La}$ Convención constituye el único tratado de derechos humanos con aspiración universal que sitúa a las normas de derechos humanos en el contexto específico de la migración.

34. La CTM aclara en el artículo 5 que los trabajadores migratorios y sus familiares:

a) Serán considerados documentados o en situación regular si han sido autorizados a ingresar, a permanecer y a ejercer una actividad remunerada en el Estado de empleo de conformidad con las leyes de ese Estado y los acuerdos internacionales en que ese Estado sea parte;

b) Serán considerados no documentados o en situación irregular si no cumplen las condiciones establecidas en el inciso a) de este artículo.

35. Entre los Estados Miembros de la CTM, pueden encontrarse en su mayoría países de origen de emigrantes pero también algunos países de tránsito y/o destino de grandes grupos de personas migrantes, como México y Turquía. Entre los Estados ratificantes, hay países de casi todas las regiones del mundo, excepto de la UE. Sin embargo, 11 Estados Miembros de la UE han ratificado uno o ambos convenios de la Organización Internacional del Trabajo que sirvieron de base para la CTM (Convenios Núms. 97 y 143 de la OIT) y, al tiempo de escribir el presente texto, dos Estados de Europa (aunque no de la UE), Turquía y Albania, son Estados Partes del CTM; ${ }^{21}$ un dato interesante si se toma en cuenta que

\footnotetext{
${ }^{19}$ Ibid., párr. 6.

${ }^{20}$ La CTM fue redactada sobre la base de dos instrumentos anteriores de la Organización Internacional del Trabajo (OIT), el Convenio sobre Trabajadores Migrantes de 1949 (No. 97) y el Convenio sobre Trabajadores Migrantes (Disposiciones Complementarias) de 1975 (No. 143). Estos tres instrumentos juntos constituyen lo que se ha denominado la "Carta Internacional de Migración"; véase TARAN, P.A., "Clashing worlds: imperative for a rights-based approach to labour migration in the age of globalization", en Vol. II Mondialisation, migration et droits de l'homme: le droit international en question/Globalization, migration and human rights: international law under review, bajo la supervisión de Vincent Chetail, Collection of the Geneva Academy of International Humanitarian Law and Human Rights, Bruylant Bruxelles (2007), p. 421.

21 Ibid.
} 
Turquía es el país receptor de la gran mayoría de las personas migrantes derivadas del conflicto armado en Siria. Mientras que muchas de estas personas serían acreedoras del estatuto de refugiado/a, otras previsiblemente se encontrarán en una situación migratoria indocumentada merecedora de la protección sobrepuesta de diferentes instrumentos jurídicos, incluida la CTM.

36. El Comité de NU para la Protección de los Derechos de Todos los Trabajadores Migratorios y de sus Familiares -el órgano de expertos independientes encargado de supervisar el cumplimiento de la CTM (artículo 72)- desempeña un papel fundamental en arrojar luz sobre las vulnerabilidades que sufren las personas migrantes, en particular las indocumentadas, y aclarar las formas concretas en que los derechos humanos de los trabajadores migrantes deben ser entendidos y aplicados. En su primera Observación General, sobre los trabajadores domésticos migratorios, de 2011, el Comité señaló que "los trabajadores domésticos migratorios corren un riesgo mayor de sufrir determinadas formas de explotación y maltrato. Esos riesgos y factores de vulnerabilidad son más graves aún en el caso de los trabajadores domésticos migratorios no documentados o en situación irregular, especialmente porque suelen correr el riesgo de expulsión si se ponen en contacto con las autoridades para solicitar protección frente a los abusos de un empleador". ${ }^{22}$

37. En este sentido, las personas migrantes indocumentadas frecuentemente se enfrentan a una doble victimización ya que, por un lado, su situación irregular las coloca en mayor riesgo de violaciones a sus derechos humanos, y por otra, su derecho humano de acceso a la justicia también se ve afectado por el miedo a la expulsión o deportación que se traduce en no acudir a denunciar las violaciones a los derechos que sufrieron en un primer momento.

38. El Parlamento Europeo ha pedido a los Estados miembros de la UE que ratifiquen la CTM ${ }^{23}$ y el ex Secretario General de NU Kofi Annan en 2004 instó a los Estados de la UE a ser Partes de la CTM. ${ }^{24}$ Sin embargo, hasta la fecha ni España, ni ningún otro Estado Miembro de la UE ha ratificado ni firmado la CTM. Aún así, cabe señalar que varios países incluyen en su legislación nacional disposiciones iguales, o muy similares, a las de la CTM. Así, España, junto con Bélgica, Italia, y Portugal, han ratificado ambos convenios de la OIT sobre trabajadores migrantes, lo cual podría abrir un posible camino para la ratificación de la $\mathrm{CTM}^{25}$

39. Independientemente de la posible ratificación futura del CTM por España, debe enfatizarse que todo el resto de los tratados internacionales de derechos humanos resultan de obligado cumplimiento para el Estado español y que le es aplicable el derecho internacional de los derechos humanos que cubre y protege a todas las personas migrantes.

40. Sin embargo, al analizar a más detalle la reacción de la UE, y de España como uno de sus Estados Miembros, sobre el respeto a los derechos humanos de las personas migrantes como una herramienta indispensable para hacer frente a la situación migratoria y de refugiados actual, se observa que ha sido ambigua y, más recientemente, ha dejado mucho que desear. Aun así, una luz de esperanza puede derivarse de algunas interpretaciones progresistas del Tribunal Europeo de Derechos Humanos y en algunos puntos del Tribunal de Justicia de la UE.

\footnotetext{
22 Comité de NU para la Protección de los Derechos de Todos los Trabajadores Migratorios y de sus Familiares, Observación General No. 1 sobre Trabajadores Migratorios Domésticos, CRMW/C/GC/1, 23 de febrero de 2011, párr. 7.

23 Parlamento Europeo, Resolution on Development and Migration, Doc P6_TA, 0319, 6 de julio de 2006.

24 United Nations Secretary-General Kofi Annan, Address to the European Parliament upon receipt of the Andrei Sakharov Prize for Freedom of Thought (Brussels), 29 de enero de 2004, disponible en www.europa-eu-un.org/articles/en/ article_3178_en.htm.

25 Véase referencias al estudio jurídico al respecto en TARAN, op. cit., p. 423.
} 


\section{EI sistema europeo de derechos humanos: Consejo de Europa y UE}

41. Al hablar de sistema europeo de derechos humanos, debemos entender el que engloba tanto las disposiciones tradicionales emanadas del Consejo de Europa, esto es, el Convenio Europeo de Derechos Humanos y Libertades Fundamentales y el resto de tratados de derechos humanos adoptados a nivel regional en este marco, así como, en el contexto más reciente, la normatividad en materia de derechos humanos y/o para nuestro tema, en materia migratoria, derivada del Derecho de la Unión Europea.

\section{Consejo de Europa}

42. En el panorama europeo la respuesta ha sido, cuando menos, ambigua con respecto a la plena protección de los derechos humanos de las personas migrantes. En el plano normativo, el Convenio Europeo sobre la Protección de los Derechos Humanos y las Libertades Fundamentales de 1950 (CEDH), y sus respectivos Protocolos, aunque no se refieren específicamente a los migrantes, resultan aplicables en la medida en que el CEDH se aplica a todas las personas bajo la jurisdicción del Estado. ${ }^{26}$ La Carta Social Europea de 1961 (CSE) y su Protocolo de 1988, así como la Carta Social Europea Revisada de 1996 (CSER), ofrecen cierto grado de protección a las personas migrantes indocumentadas, principalmente a través del derecho a la no-discriminación en relación con diferentes derechos, como los derechos laborales y las garantías de no-expulsión. ${ }^{27}$

43. España es Estado Parte del CEDH, de la CSE y su Protocolo, ${ }^{28}$ pero aún no es parte de la CSER de 1996, instrumento que contempla varios derechos económicos, sociales y culturales (DESC), y el interesante 'derecho a la protección frente a la pobreza y la exclusión social' (artículo 30), que podría funcionar como derecho llave para abrir la puerta de forma más contundente a la defensa de varios derechos específicos de las personas migrantes indocumentadas y prevenir violaciones futuras.

44. En relación con la situación particular de las mujeres migrantes indocumentadas, abordada a detalle más adelante, debe resaltarse la adopción en el marco del Consejo de Europa del Convenio sobre prevención y lucha contra la violencia contra la mujer y la violencia doméstica, adoptado en Estambul el 11 de mayo de 2011, y entrado en vigor el 1 de agosto de 2014, del cual España es Estado Parte. ${ }^{29}$ El Convenio contiene disposiciones aplicables a todas las mujeres migrantes y una protección más concreta hacia las mujeres migrantes indocumentadas, pues en su artículo 4.3 prohíbe la discriminación basada en el estatus migratorio o de refugiada al momento de la implementación de las disposiciones del Convenio.

45. Asimismo, a través de los órganos de supervisión del sistema, el Tribunal Europeo de Derechos Humanos (TEDH) (supervisor e intérprete del CEDH e instrumentos conexos); y el Comité Europeo de Derechos Sociales (de la CSE y la CSER), los derechos de los migrantes han sido, hasta cierto punto, reafirmados y protegidos. Sin embargo, el enfoque habitual del TEDH ha consistido en poner de relieve la obligación de los Estados de garantizar el derecho a la vida familiar (artículo 8) y a la no-discriminación (artículo 14) con respecto a otros derechos, en relación con personas extranjeras que residen legalmente en su territorio o que en algún momento contaron con un permiso de residencia. ${ }^{30}$

\footnotetext{
${ }^{26} \mathrm{CETS} \mathrm{N}^{\circ} 005$, abierto a la firma de los Estados miembros del Consejo de Europa el 4 de noviembre de 1950 y entró en vigor el 3 de septiembre de 1953; artículo 1.

27 CSE, CETS N ${ }^{\circ} 035$, abierto a la firma de los Estados miembros del Consejo de Europa en Turín el 18 de octubre de 1961 y entrada en vigor el 26 de febrero 1965, y CSER, CETS No. 163, abierto a la firma de la Estados miembros del Consejo de Europa el 3 de mayo de 1996 y entrada en vigor el 1 de julio de 1999.

${ }^{28}$ Instrumento de Ratificación de 29 de abril de 1980, de la Carta Social Europea, hecha en Turín de 18 de octubre de 1961. BOE, núm. 153, de 26 de junio de 1980, BOE-A-1980-13567.

29 Instrumento de ratificación del Convenio del Consejo de Europa sobre prevención y lucha contra la violencia contra la mujer y la violencia doméstica, BOE, núm. 137, de 6 de junio de 2014.

30 Véase, por ejemplo, los casos de Gaygusuz v Austria, No. 173/71/90 (1996) y Poirrez v Francia, No. $40892 / 98$ (2003). Sobre casos que abordan el tema de la expulsión de personas migrantes del territorio del Estado receptor y la validez de los requisitos nacionales de permanencia en términos de derechos humanos, véase Dalia v Francia, No. 26102/95, 19 de febrero de 1998;
} 
46. Por otro lado, aunque no directamente en materia de personas migrantes indocumentadas, pero sí en un tema relacionado, existen desarrollos progresistas respecto de los derechos de las personas solicitantes de asilo, como en el caso de M.S.S. v Bélgica y Grecia, de 2011, en el que el TEDH interpretó que el artículo 3 del CEDH (que prohíbe la tortura y los tratos inhumanos o degradantes), debía entenderse también en su dimensión socioeconómica, esto es, que el campo de la tortura y los tratos inhumanos o degradantes podía también incluir las condiciones extremas de pobreza y privación material que afectaran a personas en situación de vulnerabilidad, como las solicitantes de asilo. Así, este caso amplió el alcance del derecho a no sufrir tortura o malos tratos, aplicando el principio de no-devolución (non refoulement) también a una obligación de evitar el sufrimiento derivado de condiciones de escasez material extrema o indigencia. ${ }^{31}$ Ello constituye una vía original y prometedora para hacer este derecho más fácilmente justiciable en los casos de grave precariedad socio-económica.

47. Dicha interpretación fue seguida también por casos posteriores relativos al el principio de no devolución de personas extranjeras a un país de riesgo de tortura o tratos inhumanos degradantes, como Sufi y Elmi v. Reino Unido, de 2011, e implícitamente en S.J. v Bélgica, de 2014, aunque rechazada o denegada en otros casos como $N v$ Reino Unido, de 2008, y A.A.y Otros v Suecia, de 2012. ${ }^{32}$ En este contexto, la visión progresista y expansiva del campo de protección de los derechos adelantada por el TEDH en algunos de los casos, pudiera extrapolarse a las condiciones de vida de las personas migrantes indocumentadas a fin de promover las obligaciones positivas del Estado -y no sólo o prioritariamente las obligaciones de 'no hacer'-, para la consecución de sus derechos, particularmente los DESC.

48. Al igual que en el caso de los órganos de supervisión de tratados del sistema de Naciones Unidas, los órganos del sistema del Consejo de Europa y el TEDH, se han pronunciado sobre distintos casos concernientes a España, que se estudiarán de forma temática en cada sección correspondiente del apartado subsecuente referido al caso español.

49. A pesar de la existencia de la arquitectura jurídica formal de derechos humanos proveniente del Consejo de Europa, la fuente de preocupación mayor en materia de la garantía y protección de los derechos humanos de las personas migrantes proviene no sólo de los retos prácticos que conlleva la implementación de dicho marco jurídico a nivel nacional, sino de las disposiciones en muchas ocasiones contrarias a los derechos humanos en el propio Derecho de la UE. En efecto, cómo se verá a detalle en el apartado siguiente, existe una fuerte crítica en el ámbito de los derechos humanos hacia la aplicación de la Directiva de Retorno de la UE (2008) y el aumento indiscriminado en los últimos años de detenciones a personas migrantes irregulares, incluidos niños y niñas, y su retorno casi inmediato a sus países de origen, sin el respeto obligado a su derecho humano al debido proceso y las garantías judiciales necesarias. ${ }^{33}$

Slivenko et al. v Latvia, No. 48321/99, 9 de octubre de 2003 (Gran Sala); Maslov v Austria, No. 1638/03, 28 de mayo de 2003 (Gran Sala); y Trabelsi v Alemania,ent of 13 October 2011, No. 41548/06, 13 de octubre de 2011 (disponible sólo en francés).

31 TEDH, M.S.S. v. Bélgica y Grecia, No. 30696/09, 21 de enero de 2011, en especial párrs. 246 y 254. Para un estudio detallado del caso y sus implicaciones para el sistema más general de la UE en materia de asilo, el 'Sistema Dublín', véase V. Moreno-LaX, 'Dismantling the Dublin System: M.S.S. v Belgium and Greece', European Journal of Migration and Law, 14 (1), 2012, pp. 1-31

32 TEDH, Sufi y Elmi v. Reino Unido, Nos. 8319/07 y 11449/07, 28 de junio de 2011, en especial párrs. 279 y 283; y SJv Belgium, No. 70055/10, que fue resuelto mediante una solución amistosa del 26 de agosto de 2014 y el posterior otorgamiento por el gobierno belga de los permisos de residencia permanentes a la mujer nigeriana enferma de VIH-SIDA denunciante en el caso, y a sus hijos. Véase Nv Reino Unido, No 26565/05, 27 de mayo de 2008 (Gran Sala); A.A. y Otros v Suecia, No. 14499/09, 28 de junio de 2012 (sentencia final de 28 de septiembre de 2012), y Opinión Disidente de la Juez Ann Power-Forde en este último caso, oponiéndose a la decisión mayoritaria de denegar la protección del TEDH a dos mujeres de Yemen en riesgo de expulsión de Suecia.

33 Véase la declaración más reciente en este sentido, "New EU recommendation on return procedures a "slippery slope" to solve European migration challenges - UN experts', Chair of the Subcommittee on the Prevention of Torture, Sir Malcolm Evans; Special Rapporteur on the human rights of migrants, François Crépeau; Chair of the Committee on the Protection of the Rights of All Migrant Workers and Members of Their Families, Jose S. Brillantes; Chair of the Committee on the Rights of the Child, Benyam Dawit Mezmur; Chair of the Working Group on Arbitrary Detention, Sètondji Roland Adjovi; Comunicado de prensa de expertos de Naciones Unidas en materia de derechos humanos, 9 de marzo de 2017, disponible en http://www.ohchr. org/EN/NewsEvents/Pages/DisplayNews.aspx?NewsID=21330\&LangID=E\#sthash.O9cHLyMF.dpuf. 


\section{Unión Europea}

50. Con base en las normas generales de derechos humanos contenidas en el Tratado de la Unión Europea (TUE), en sus artículos 2 y 3 , y el reconocimiento en su preámbulo a la dignidad humana como fundamento de la Carta de Derechos Fundamentales de la UE del 2000 -jurídicamente obligatoria para los Estados Miembros de la UE con base en el Tratado de Lisboa en vigor desde 2009-, pueden reafirmarse los derechos humanos de las personas migrantes como condición indispensable para su supervivencia y para una vida digna.

51. Como marco general para el análisis de este apartado, debe recordarse también que de conformidad con el artículo 79 del Tratado de Funcionamiento de la Unión Europea (TFUE), la Unión desarrollará una política común de inmigración. Esta política está destinada, según el mismo artículo, a gestionar eficazmente los flujos migratorios, a garantizar un trato equitativo de los nacionales de terceros países que residan legalmente en los Estados miembros, así como a prevenir y luchar contra la inmigración ilegal y la trata de seres humanos. La Unión podrá también, con base en el apartado tercero del mismo artículo, celebrar con terceros países acuerdos para la readmisión, en sus países de origen o de procedencia, de nacionales de terceros países que no cumplan o que hayan dejado de cumplir las condiciones de entrada, presencia o residencia en el territorio de uno de los Estados miembros. La ejecución de esta política, añade el artículo 80 TFUE, se regirá por el principio de solidaridad y de reparto equitativo de la responsabilidad entre los Estados miembros, también en el aspecto financiero.

52. La competencia de la Unión en este ámbito es compartida con los Estados miembros, por lo que éstos podrán realizar actos jurídicos vinculantes en la medida en que la Unión Europea no haya ejercido su competencia con arreglo al artículo 4 TFUE. En este sentido, por ejemplo, el apartado 5 del artículo 79 TFUE permite a los Estados miembros establecer volúmenes de admisión en su territorio de nacionales de terceros países procedentes de terceros países con el fin de buscar trabajo por cuenta ajena o por cuenta propia. Los actos jurídicos que la Unión adopte en esta materia se regirán por el procedimiento legislativo ordinario, salvo en el caso de emergencia derivada de la afluencia repentina de nacionales de terceros países, cuando el Consejo podrá adoptar, a propuesta de la Comisión y previa consulta al Parlamento Europeo, medidas provisionales en beneficio de los Estados miembros afectados. Finalmente, el Tribunal de Justicia (TJUE) goza de jurisdicción plena en este ámbito competencial. ${ }^{34}$

53. La Unión ha adoptado diversas medidas legislativas en materia de inmigración, tanto en relación con la inmigración legal, ${ }^{35}$ como en relación con la inmigración denominada como ilegal por el TFUE. A los efectos de este trabajo nos centraremos en estas últimas. Estas medidas han ido destinadas esencialmente a luchar contra la inmigración irregular, adoptando un enfoque más centrado en la segu-

${ }^{34}$ Sobre la difícil delimitación de la competencia de la UE en este ámbito véase, por ejemplo, J.C. FERnÁNDEZ RozAs, Control de fronteras, asilo e inmigración en la Unión Europea: un conflicto competencial no resuelto”, en J.M., BAÑo LEÓN (COORD.), Memorial para la Reforma del Estado. Estudios en homenaje al profesor Santiago Muñoz Machado, t. I, Madrid, Centro de Estudios Constitucionales, 2016, pp. 333-378, especialmente pp. 364-365.

35 Véanse a este respecto, por ejemplo, la Directiva 2009/50/CE, de 25 de mayo de 2009, relativa a las condiciones de entrada y residencia de nacionales de terceros países para fines de empleo altamente cualificado. DO L 155/17, 18.6.2009; Directiva 2011/98/UE del Parlamento Europeo y del Consejo, de 13 de diciembre de 2011, por la que se establece un procedimiento único de solicitud de un permiso único que autoriza a los nacionales de terceros países a residir y trabajar en el territorio de un Estado miembro y por la que se establece un conjunto común de derechos para los trabajadores de terceros países que residen legalmente en un Estado miembro, DO L 343, 23.12.2011, p. 1-9; Directiva 2014/36/UE del Parlamento Europeo y del Consejo, de 26 de febrero de 2014 , sobre las condiciones de entrada y estancia de nacionales de terceros países para fines de empleo como trabajadores temporeros DO L 94 de 28.3.2014, p. 375/390; Directiva 2014/66/UE del Parlamento Europeo y del Consejo, de 15 de mayo de 2014, relativa a las condiciones de entrada y residencia de nacionales de terceros países en el marco de traslados intraempresariales, DO L 157, 27.5.2014, p. 1-22; o Directiva (UE) 2016/801 del Parlamento Europeo y del Consejo, de 11 de mayo de 2016, relativa a los requisitos de entrada y residencia de los nacionales de países terceros con fines de investigación, estudios, prácticas, voluntariado, programas de intercambio de alumnos o proyectos educativos y colocación au pair. DO 132, de 21.05.2016, pp. 21 a 57. 
ridad de las fronteras que en los derechos de las personas migrantes. Así, la Directiva 2002/90/CE, ${ }^{36}$ estableció una definición común del delito de ayuda a la entrada, a la circulación y a la estancia irregular. ${ }^{37}$ Esta Directiva fue complementada por la Decisión marco 2002/946/JAI, ${ }^{38}$ que regulaba las sanciones penales que se debían imponer por las conductas tipificadas por la Directiva 2002/90/CE y por la Directiva 2004/81/CE del Consejo, que preveía la expedición de un permiso de residencia a víctimas de la trata o del tráfico ilícito de seres humanos que cooperasen con las autoridades competentes..$^{39}$ Asimismo se ha adoptado más recientemente la Directiva 2009/52/CE, que establece sanciones y medidas aplicables en los Estados miembros a los empleadores de ciudadanos de terceros países en situación irregular. ${ }^{40}$

54. Una de las medidas legislativas más controvertidas ha sido la conocida como Directiva de Retorno, es decir, la Directiva 2008/115/C relativa a normas y procedimientos comunes en los Estados miembros para el retorno de los nacionales de terceros países en situación irregular. ${ }^{41}$ Esta directiva, que hace referencia en su artículo 1 a la necesidad de respetar en su aplicación los derechos fundamentales y el Derecho internacional, ${ }^{42}$ ha sido objeto de fuertes críticas, precisamente por contribuir, inter alia, a la generalización de la detención e internamiento de los inmigrantes de manera sistemática, y a la vulneración por parte de los Estados miembros de obligaciones internacionales relativas a las personas migrantes, como la Convención de Naciones Unidas sobre los Derechos del Niño, que no prevé el internamiento de menores por su situación migratoria o la de sus padres, algo que la Directiva sí permite..$^{43}$ Asimismo, se han criticado las situaciones de abuso que ha ocasionado la transposición de la Directiva en los distintos niveles nacionales, así como las implicaciones negativas para los derechos humanos de la aplicación práctica de la misma. ${ }^{44}$

55. En atención a estas preocupaciones, el Parlamento Europeo ha subrayado recientemente que el retorno de los migrantes sólo debe llevarse a cabo de forma segura, con plena observancia de los derechos fundamentales y procesales de los migrantes, y que "cualquier intento por parte de los Estados miembros de «hacer retroceder» a los migrantes a los que no se les haya dado la oportunidad de pre-

36 Directiva 2002/90/CE del Consejo, de 28 de noviembre de 2002, destinada a definir la ayuda a la entrada, a la circulación y a la estancia irregulares. DO núm. 328, de 5.12.2002, pp. 17-18.

37 El artículo 1 de esta Directiva, titulado Tipificación general, establecía la obligación de adoptar sanciones "contra cualquier persona que intencionadamente ayude a una persona que no sea nacional de un Estado miembro a entrar en el territorio de un Estado miembro o a transitar a través de éste, vulnerando la legislación del Estado de que se trate sobre entrada o tránsito de extranjeros $[\mathrm{y}]$ contra cualquier persona que intencionadamente ayude, con ánimo de lucro, a una persona que no sea nacional de un Estado miembro a permanecer en el territorio de un Estado miembro, vulnerando la legislación del Estado de que se trate sobre estancia de extranjeros." Este artículo permitía, en su apartado segundo, no adoptar sanciones en el primero de los supuestos si el objetivo de la conducta era prestar ayuda humanitaria.

38 Decisión marco del Consejo, de 28 de noviembre de 2002, destinada a reforzar el marco penal para la represión de la ayuda a la entrada, a la circulación y a la estancia irregulares, DO L 328 de 5.12.2002, pp. 1/3

39 Directiva 2004/81/CE del Consejo relativa a la expedición de un permiso de residencia a nacionales de terceros países que sean víctimas de la trata de seres humanos o hayan sido objeto de una acción de ayuda a la inmigración ilegal, que cooperen con las autoridades competentes. DO L 261/19, 6.8.2004.

40 Directiva 2009/52/CE del Parlamento Europeo y del Consejo, de 18 de junio de 2009, por la que se establecen normas mínimas sobre las sanciones y medidas aplicables a los empleadores de nacionales de terceros países en situación irregular. DO L 168 de 30.6.2009, p. 24/32.

${ }^{41}$ Directiva 2008/115/CE del Parlamento Europeo y del Consejo, de 16 de diciembre de 2008, relativa a normas y procedimientos comunes en los Estados miembros para el retorno de los nacionales de terceros países en situación irregular. DO núm. 348, de 24.12.2008, pp. 98-107.

42 En concreto el artículo 1 de la Directiva señala que se deberán respetar "los derechos fundamentales como principios generales del Derecho comunitario, así como del Derecho internacional, incluidas las obligaciones en materia de protección de los refugiados y de derechos humanos."

43 Véase a este respecto, por ejemplo, L.C., NIETO GARCíA, "Derechos humanos e inmigración: Europa y la directiva de retorno", Papeles de relaciones ecosociales y cambio global, No. 104, 2008-2009, pp. 39-56; N., Pérez Sola, "La directiva de retorno y la involución en la Europa de los derechos", Revista de estudios jurídicos, № 8, 2008, pp. 241-256; o el detallado informe de PICUM (Platform for International Cooperation on Undocumented Migrants), titulado "Posición de PICUM sobre la directiva de retorno de la UE", abril 2015. El informe se puede consultar en español en el siguiente enlace: http://picum.org/picum.org/ uploads/publication/ReturnDirective_PositionPaper_ES.pdf

44 Véase, e.g., N. Vavoula, 'Detention of Irregular Migrants - The Returns Directive Shows its True Colours In Mahdi (C-146/14 PPU)' in European Law Blog, 15 de septiembre de 2014, disponible en http://europeanlawblog.eu/?p=2501. 
sentar solicitudes de asilo es contrario al Derecho Internacional y de la UE, y que la Comisión debería tomar medidas adecuadas contra cualquier Estado miembro que lo intente." ${ }^{\prime 5}$ Ello complementa las interpretaciones judiciales en este sentido del TEDH, por ejemplo, en el caso de Hirsi v Italia, de 2012.46

56. Por último, en relación con la aplicación de la Directiva de Retorno en España, a raíz de una cuestión prejudicial planteada por el Tribunal Superior de Justicia del País Vasco, el Tribunal de Justicia de la Unión Europea concluyó recientemente en 2015 que la previsión de la Ley de Extranjería española que permitía sustituir la expulsión de un inmigrante en situación irregular por la imposición de una multa (artículo 57.1 en relación con el 53) vulneraba la directiva al hacer más difícil la consecución de su efecto útil. ${ }^{47}$ Dicha interpretación perjudica la situación de las personas migrantes indocumentadas en España dado que disminuye las opciones jurídicas al alcance de la autoridad relevante. Antes como resultado de la estancia irregular de una persona en el país, se le podía aplicar la sanción menos perjudicial de la multa y ahora a la luz de la postura del TJUE sólo podría sancionársele con la expulsión (aunque es verdad también que la disposición relevante de la Ley de Extranjería no se ha modificado y sigue aplicándose en la práctica).

57. Por otro lado, conviene recordar en este contexto que los Estados miembros están obligados a respetar los derechos fundamentales de las personas migrantes reconocidos por el Derecho de la Unión cuando actúan en el ámbito de aplicación del mismo. ${ }^{48}$ Tras la entrada en vigor del Tratado de Lisboa en 2009, y la adquisición de carácter vinculante de la Carta de Derechos Fundamentales de la Unión Europea, esta obligación se establece con claridad en el artículo 51 de la misma, y así lo ha interpretado repetidamente el Tribunal de Justicia de la Unión. ${ }^{49}$ De esta forma, por ejemplo, cuando los Estados miembros desarrollan y aplican las garantías a la espera del retorno recogidas en el artículo 14 de la Directiva de Retorno, deberán observar los derechos y estándares establecidos por la Carta de Derechos Fundamentales de la Unión y la jurisprudencia que la interpreta. ${ }^{50}$

58. Asimismo, de la jurisprudencia del TJUE también se desprende que los nacionales de terceros países podrán verse beneficiados por los derechos reconocidos por el Derecho de la Unión Europea, en este caso los dimanantes del estatuto de ciudadano de la Unión Europea, si la denegación de su permiso de residencia en un Estado miembro de la Unión tendría por efecto privar a los ciudadanos de la Unión, en este caso sus descendientes, del disfrute efectivo de la esencia de los derechos conferidos por su condición de ciudadanos de la Unión. ${ }^{51}$

59. En este marco, la arquitectura jurídica de la política migratoria de la Unión ha sido puesta a prueba recientemente por la denominada "crisis migratoria" de 2015, caracterizada por la afluencia masiva de inmigrantes, la mayoría solicitantes de asilo, al este de Europa. Uno de los instrumentos más reconocibles de la respuesta de la UE a este fenómeno ha sido el conocido como acuerdo UE-Turquía. En

45 Resolución del Parlamento Europeo, de 12 de abril de 2016, sobre la situación en el mar Mediterráneo y necesidad de un enfoque integral de la Unión sobre la migración (2015/2095(INI)), apartados 60 y 61 .

46 Hirsi Jamaa y Otros v Italia, No. 27765/09, 23 de febrero de 2012.

47 TRIBUNAL DE JUSTICIA de LA UE (Sala Cuarta), Sentencia de 23 de abril de 2015, C-38/14. Véase en relación con dicha sentencia, K. CASTILla JuÁrez, "Migración sine permissum en España: multa, expulsión y non bis in idem. Más allá de lo constitucionalmente admisible y acorde con la normativa europea." Revista de Derecho Migratorio y Extranjería, No. 42, Mayo - Agosto 2016, pp. 87-110.

48 Véase a este respecto, por ejemplo, la sentencia del TJUE en el asunto C-299/95, Kremzow, 29 mayo 1997, apartado 15.

49 Sentencia del TJUE en el asunto C-617/10, Åkerberg Fransson, 26 Febrero 2013. Véase en relación con el ámbito de aplicación de la Carta, D. SARmiEnto, "Who's afraid of the Charter? The Court of Justice, national courts and the new framework of fundamental rights protection in Europe", CMLR, Vol. 50, No. 5, octubre 2013, pp. 1267-1304.

50 Véase a este respecto, por ejemplo, el informe de la Agencia de Derechos Fundamentales de la Unión Europea titulado "Fundamental rights of migrants in an irregular situation in the European Union", Publicaciones Oficiales de la Unión Europea, Luxemburgo, 2011, p. 25.

51 Sentencias de 8 de marzo de 2011, Ruiz Zambrano, C-34/09, EU:C:2011:124, apartado 42, de 6 de diciembre de 2012, O. y otros, C-356/11 y C-357/11, EU:C:2012:776, apartado 45, y más recientemente de 10 de mayo de 2017, H.C. ChávezVílchez, C-133/15, apartado 61, no publicada aún al momento de redacción del presente texto. 
virtud de este acuerdo "Todos los nuevos migrantes irregulares que pasen de Turquía a las islas griegas a partir del 20 de marzo de 2016 serán retornados a Turquía; Los migrantes que lleguen a las islas griegas serán debidamente registrados y las autoridades griegas tramitarán toda solicitud de asilo individualmente, de acuerdo con la Directiva sobre procedimientos de asilo; Los migrantes que no soliciten asilo o cuya solicitud se haya considerado infundada o inadmisible serán retornados a Turquía; Por cada sirio retornado a Turquía desde las islas griegas, se reasentará a otro sirio procedente de Turquía en la Unión." ${ }^{52}$

60. Este acuerdo ha sido criticado por su posible vulneración del Derecho internacional y europeo de los derechos humanos y también del Derecho de la Unión Europea, que prohíben, inter alia, las expulsiones colectivas en el artículo 4 del Protocolo núm. 4 al CEDH y artículo 19.1 de la Carta de Derechos Fundamentales de la UE, así como por externalizar el control de las migraciones a la Unión Europea hacia Turquía, haciendo más difícil el control del respeto a los derechos fundamentales de los migrantes. Este riesgo se ha incrementado notablemente tras negarse el Tribunal General, mediante autos de 28 de febrero de 2017, a aceptar su jurisdicción sobre el Acuerdo UE-Turquía, por considerar que se trata de un acto que no fue adoptado por las instituciones de la Unión sino por los Estados miembros. ${ }^{53}$ Esta decisión ha sido recurrida ante el Tribunal de Justicia, y se encuentra pendiente de resolución al momento de redacción del presente texto. ${ }^{54}$

\section{Marco jurídico y práctica en España a la luz de los derechos humanos}

61. De manera similar a toda el área del norte del Mediterráneo, España está experimentado en la actualidad el fenómeno de la inmigración a gran escala por primera vez en su historia moderna, y el flujo migratorio y de refugiados a Europa más grande desde la Segunda Guerra Mundial.

62. En ese contexto, la Constitución Española (CE), en su artículo 10 proclama la dignidad de la persona, reconociendo los derechos inviolables que le son inherentes e indicando que las normas relativas a los derechos fundamentales que la Constitución reconoce se interpretarán de conformidad con la Declaración Universal de Derechos Humanos y los tratados y acuerdos internacionales sobre las mismas materias ratificados por España, instrumentos con base en los cuales -como se ha visto en los apartados anteriores- se reconocen los derechos humanos de todas las personas, independientemente de su origen nacional o estatus migratorio.

63. Sin embargo, este marco normativo general contrasta con otras disposiciones jurídicas de inferior jerarquía, así como con obstáculos prácticos, que conjunta y acumulativamente, permiten, facilitan o directamente provocan distintas violaciones a derechos humanos experimentadas por las personas migrantes. A continuación se sistematizan -de manera propositiva y de ningún modo exhaustiva-, algunas de las principales situaciones de afectación a los derechos de las personas migrantes indocumentadas, agrupándolas de acuerdo a la situación jurídico-administrativa, el tipo de derecho(s) y/o el daño sufrido:

\section{Retos generales, igualdad y no-discriminación}

64. El principal problema que enfrentan las personas migrantes indocumentadas en España para la realización efectiva de sus derechos humanos se encuentra en la ley misma. En efecto, la Ley Orgánica 4/2000, de 11 de enero, sobre derechos y libertades de los extranjeros en España y su integración social (Ley de Extranjería o LOEX) ${ }^{55}$ al abordar las infracciones 'leves', 'graves' y 'muy graves' de la propia Ley, establece que es una infracción 'grave',

\footnotetext{
52 Véase este resumen del acuerdo en el comunicado de prensa del Tribunal General $\mathrm{n}^{\circ} 19 / 174$, de 28 de febrero de 2017.

53 Autos del Tribunal General en los asuntos T-192/16, T-193/16 y T-257/16 NF, NG y NM / Consejo Europeo, no publicados aún.

54 NF v European Council, C-208/17 P.

55 BOE núm. 10, de 12 de enero de 2000. Última modificación: 30 de octubre de 2015. Referencia: BOE-A-2000-544.
} 
encontrarse irregularmente en territorio español por no haber obtenido la prórroga de estancia, carecer de autorización de residencia o tener caducada más de tres meses la mencionada autorización, y siempre que el interesado no hubiere solicitado la renovación de la misma en el plazo previsto reglamentariamente (Artículo 53,a.).

65. Por su parte, el mismo artículo 53, en su inciso b., también incluye como infracción grave "Encontrarse trabajando en España sin haber obtenido autorización de trabajo o autorización administrativa previa para trabajar, cuando no cuente con autorización de residencia válida".

66. Ello además de posibilitar la expulsión de la persona extranjera con base en el artículo 57 de la LOEX -facultad que resulta reforzada con la Directiva de Retorno de la UE antes analizada-, coloca a toda persona que por distintas razones pueda encontrarse en situación irregular (bien sea por haber ingresado de forma irregular en el territorio, bien sea por haber excedido el tiempo de su visa, o haber cambiado las circunstancias que dieron lugar al otorgamiento de su permiso de residencia), en una condición de miedo, inseguridad y vulnerabilidad constante y perpetuada. ${ }^{56}$

67. Ello es así máxime si consideramos que la alternativa más frecuentemente accesible para una persona migrante indocumentada para regularizar su situación es la conocida figura del 'arraigo social', prevista en los artículos 31.3 y 68.3 de la LOEX y 124 de su Reglamento, para cuya obtención hay que esperar nada menos que tres años de presencia continuada en España, sin trabajar, y al final de dicho tiempo presentar, entre otros requisitos, un contrato de trabajo por un periodo mínimo de un año, requisito del cual se le exime únicamente si logra probar que cuenta con medios económicos suficientes.

68. Tales exigencias tan estrictas no solamente vuelven sumamente difícil la obtención de la autorización de residencia por arraigo social, sino que orilla a las personas indocumentadas a buscar formas de sobrevivir desde la clandestinidad, viendo con ello afectados sus derechos humanos universalmente reconocidos. Entre esos derechos, y como presupuesto básico que abre la puerta al disfrute de muchos otros derechos, se encuentra el derecho humano a la personalidad jurídica, previsto desde la DUDH de 1948 en los siguientes términos:

Todo ser humano tiene derecho, en todas partes, al reconocimiento de su personalidad jurídica. ${ }^{57}$

69. La situación de 'limbo jurídico' que viven las personas migrantes indocumentadas contradice este derecho humano y despliega también otras consecuencias. Contribuye a la normalización en la vida cotidiana de esa exclusión legal. Conduce a la aprobación y la facilitación de la segregación social, económica y política de las y los migrantes indocumentados por parte del Derecho. Y permite la construcción de un grupo de personas "de segunda clase", como ya lo advertía el Relator Especial de NU en la materia, y a la vez de una "sociedad del menosprecio". 58

70. Dicho conjunto de disposiciones de la LOEX y relacionadas, pudiera además constituir discriminación por motivos de raza y/o por estatus socio-económico. Si sólo se admite plenamente a inmigrantes con medios económicos suficientes y la política y normatividad migratoria se basa en una lógica de poder adquisitivo y en el binomio 'rico-aceptable' / 'pobre-inadmisible y expulsable', ${ }^{59}$ deja-

56 Véase E. Lester, 'Socio-Economic Rights, Human Security and Survival Migrants: Whose Rights? Whose Security?', en A. Edwards y C. Ferstman (editoras), Human Security and Non-Citizens: Law, Policy and International Affairs, Cambridge, Cambridge University Press, 2010. En un sentido similar, particularmente centrado en el tema de refugio, véase J. HuYSMANS, The Politics of Insecurity. Fear, migration and asylum in EU, Routledge, London, 2006.

57 Artículo 6 de la DUDH, cursivas propias. Véase en el sentido de las condiciones de clandestinidad, COMITÉ DE NU PARA LA Protección de los Derechos de Todos los Trabajadores Migratorios y de sus Familiares, Observación General No 2 sobre los Derechos de los Trabajadores Migrantes en una Situación Irregular y Miembros de sus Familias, 23 de agosto de 2013, punto I.2.

58 J. DE LuCAS (editor), Inmigración e integración en la UE: dos retos para el s. XXI, Eurobask, 2012, pp. 11-13.

59 Como elemento que refuerza de este binomio, cabría mencionar la posibilidad prevista por la Ley 14/2013, de 27 de septiembre, de apoyo a los emprendedores y su internacionalización, de obtener un visado de residencia por adquisición de 
ríamos completamente inoperantes las afirmaciones de igualdad y las prohibiciones de discriminación que, como se ha descrito en los apartados anteriores, constituyen la base del derecho internacional de los derechos humanos y el fundamento de las sociedades democráticas.

71. Respecto del ámbito de la discriminación racial en relación con las personas migrantes, debe señalarse la muy reciente presentación de un caso contra España ante el TEDH. El 8 de mayo de 2017 se presentó ante dicho tribunal, una demanda contra el Estado español por no tomar medidas efectivas contra las identificaciones policiales por perfil étnico, a raíz de prejuicios basados en el color de la piel de las personas. La demanda presentada ante el TEDH argumenta que parar una persona por tales prejuicios, lo que se conoce como "perfil étnico" ("ethnic profiling"), vulnera el derecho a no ser discriminado, reconocido en el Artículo 14 y el Protocolo 12 del CEDH y el derecho a la vida privada, recogido en el artículo 8 del mismo Convenio. Aunque el afectado por el caso, el Sr. Zeshan Muhammad, un hombre de raza negra, es un migrante documentado en tanto que cuenta con permiso de residencia y vive cerca de Barcelona desde que era niño, el argumento es directamente aplicable a la discriminación por origen étnico que experimentan muchas personas migrantes (documentadas e indocumentadas), y en general cualquier persona no caucásica, pues aborda la práctica más amplia de la detención por parte de la policía de todas aquellas personas no blancas, con base simplemente en el color de su piel, su fenotipo o su apariencia física ${ }^{60}$ Con el apoyo de varias organizaciones, el Sr. Muhammad lleva a cabo este litigio estratégico con el fin no sólo de que se reconozca la violación de sus derechos y obtener reparaciones, sino también de lograr terminar con esta práctica policial discriminatoria que sufre una parte importante de la población, y que ya había sido antes determinada como violatoria por el Comité de Derechos Humanos de NU (órgano revisor del cumplimiento del PIDCP), en otro caso similar, Rosalind Williams v España. ${ }^{61}$

72. El caso Zeshan Muhammad ante el TEDH complementa además el litigio anterior de B.S. $v$ España, ya resuelto por ese tribunal en 2012, con la conclusión de que había existido violación del artículo 3 del CEDH (como se ha visto, referido a la prohibición de tortura y tratos inhumanos o degradantes), en su vertiente procesal; del artículo 14 del mismo instrumento (prohibición de discriminación), en relación al propio artículo 3, debido a la ausencia de una investigación efectiva respecto a las denuncias de malos tratos formuladas por la demandante -una mujer extranjera, de raza negra, que ejercía la prostitución y que denunció haber sido golpeada con porras en la calle y haber recibido insultos racistas por parte de funcionarios de policía. ${ }^{62}$

73. Así pues, existe por una parte un reconocimiento del Estado español de la presencia de las personas migrantes indocumentadas en el territorio nacional y una voluntad política -expresada en ciertos ordenamientos normativos protectores de derechos-, de atender su condición de vulnerabilidad.

74. Por otra parte, la circunstancia de las personas migrantes indocumentadas parecería reflejar lo que Michel Foucault llamaba desde los años setenta del siglo pasado, la aplicación del control biopolítico o el biopoder, como fenómeno característico del Estado moderno consistente en entender a la población "como problema biológico y como problema de poder", y por ello, sujeto de control y de regulación minuciosa por parte del Estado. ${ }^{63}$ En efecto, bajo esta óptica, la situación y los derechos de las

bien inmueble en España con una inversión de valor igual o superior a 500.000 euros. Véase también de modo más general J. Harding, Border Vigils: Keeping Migrants out of the Rich World, London/New York, Verso Books, 2012.

60 El Sr. Muhammad fue parado por un agente de la Policía Nacional en Barcelona el 29 de mayo de 2013. El policía admitió que no hubiera parado una persona blanca y afirmó que lo hacía “iporque eres negro, y punto!”. Las organizaciones que llevan a cabo el litigio en apoyo del afectado son SOS Racisme Catalunya y Open Society Justice Initiative; véase https:// sosracismo.eu/tedh-perfil-etnico/\#more-2767

${ }_{61}$ Véase Comité de Derechos Humanos de NU, Rosalind Williams v España, CCPR/C/96/D/²493/2006, 30 de julio de 2009, en especial, párrs. 8 y 9.

62 B.S. v. España, No. 47159/08, 24 julio 2012.

63 M. Foucault, Genealogía del racismo, Editorial Altamira, Argentina, 1976, p. 198. En esta línea, y con un enfoque específicamente centrado en la cuestión migratoria, véase también N. VAUGHAN-Williams, Europe's Border Crisis: Biopolitical Security and Beyond, Oxford University Press, 2015. 
personas migrantes indocumentadas se encuentran permanentemente sujetos a la decisión (en ocasiones injustificada) del Estado y a las altas y bajas de su política migratoria en función de condiciones económicas, políticas y sociales del país receptor, y no de su igual dignidad como personas y la universalidad de sus derechos humanos.

\section{Derecho humano a la salud y otros derechos económicos, sociales y culturales (DESC)}

75. Un derecho humano que ven comprometido con frecuencia las personas migrantes en España es el derecho a la salud, así como en general los derechos económicos, sociales y culturales (DESC), como el derecho a la vivienda, el derecho a la educación o el derecho al agua. ${ }^{64}$

76. Particularmente el derecho a la salud de las personas migrantes indocumentadas se ha visto afectado de manera mucho más pronunciada a raíz del Real Decreto-Ley 16/2012, de 20 de abril de 2012 (RDL 16/2012), "Medidas urgentes para garantizar la sostenibilidad del Sistema Nacional de Salud y mejorar la calidad y seguridad de sus prestaciones". La aplicación del RDL 16/2012 se tradujo en la limitación del derecho al acceso a la salud para las personas no inscritas en el Régimen de la Seguridad Social, afectando así la atención sanitaria gratuita y universal para todas las personas bajo la jurisdicción del Estado español. ${ }^{65}$ Como consecuencia de la aplicación de este Real Decreto-Ley se ha generado un acceso desigual a un derecho humano básico, legal e internacionalmente reconocido.

77. Por su parte, la Constitución Española en su artículo 15 recoge el derecho fundamental a la vida y a la integridad física y moral, el artículo 43 reconoce el derecho a la protección de la salud y el artículo 45 explicita a su vez que todos los ciudadanos y ciudadanas tienen el derecho a disfrutar de un medio ambiente adecuado para el desarrollo de la persona, así como el deber de conservarlo.

78. Cabe destacar además que la redacción del artículo 43.1 de la CE, a diferencia de otras disposiciones, al referirse a los sujetos destinatarios de la norma lo hace de manera indeterminada ("se reconoce"), con lo que "el mandato constitucional parecería evocar la terminología universalista presente en los tratados internacionales de derechos humanos respecto a la titularidad del derecho a la protección sanitaria". ${ }^{66}$ En efecto, tales tratados de derechos humanos, de los que España es Estado Parte, como se estudió en los apartados anteriores, amparan el derecho a la atención sanitaria integral (esto es, no únicamente de urgencia) utilizando una postura de subjetividad universal, cubriendo también en consecuencia a los inmigrantes en situación administrativa irregular.

79. Con base en la normativa de derechos humanos, España se encuentra particularmente obligada a observar el derecho a la no-discriminación en relación con el derecho humano a la salud, en aplicación de los Artículos 10, 13, 14 y 43 de la Constitución Española; y en los Artículos 2 y 12 del Pacto Internacional de Derechos Económicos, Sociales y Culturales; del Artículo 14 en relación con los Artículos 2 y 3 de la CEDH; y de los Artículo 21 y 35 de la Carta de Derechos Fundamentales de la Unión Europea. En el caso concreto de personas en situación de vulnerabilidad, como las personas migrantes indocumentadas, esta obligación se vuelve particularmente importante, como se reitera en la Observación General No. 14 del Comité de Derechos Económicos, Sociales y Culturales de Naciones Unidas, del año 2000 (órgano interpretador del PIDESC), que al efecto establece que:

\footnotetext{
${ }^{64}$ Véase, e.g., S. SPEncer y V. Hughes, 'Outside and In: Legal Entitlements to Health Care and Education for Migrants with Irregular Status in Europe', Centre on Migration, Policy, and Society (COMPAS), Universidad de Oxford, 2015.

65 Véase REDER (Red de Denuncia y Resistencia al RDL 16/2012), 'Radiografía de la reforma sanitaria: la universalidad de la exclusión', Madrid, septiembre de 2015.

${ }^{66}$ I. Sobrino GujJarRo, 'Inmigrantes irregulares y el derecho a la protección de la salud: análisis de la reforma sanitaria en España', en Lex Social. Revista Jurídica de los Derechos Sociales, Vol. 3, núm. 2/2013, julio-diciembre 2013, p. 151. Véase el estudio integral de la autora sobre el derecho a la salud de personas migrantes irregulares desde la perspectiva de derechos humanos.
} 
"Los Estados partes tienen la obligación de respetar el derecho a la salud garantizando que todas las personas, incluidos los migrantes, tengan igualdad de acceso a los servicios de salud preventivos, curativos y paliativos, independientemente de su condición jurídica y su documentación” (párr. 34).

80. Dicha obligación fue reiterada en la Declaración del Comité DESC, 'Obligaciones de los Estados con respecto a los refugiados y los migrantes en virtud del Pacto Internacional de Derechos Económicos, Sociales y Culturales' (párrafo 12), emitida muy recientemente, el 13 de marzo de 2017. Asimismo, en dicha Declaración, el Comité DESC enfatiza que la dificultad o imposibilidad de que los migrantes indocumentados obtengan prestaciones de la seguridad social aumenta su vulnerabilidad.

81. En el contexto más general de los DESC, cabe destacar también que el 10 de diciembre de 2008 la AGNU aprobó el Protocolo Facultativo del PIDESC, en vigor desde el 5 de mayo de 2013, como instrumento jurídico accesorio al propio PIDESC (del cual España es Estado Parte, como se mencionó arriba), que permite la presentación de quejas individuales por violaciones a los derechos humanos contemplados en dicho Pacto, a presentarse ante el Comité DESC. Con ello, los derechos económicos, sociales y culturales se vuelven plenamente exigibles y justiciables internacionalmente, con la misma jerarquía que los derechos civiles y políticos.

82. España fue el primer país europeo en ratificar el Protocolo Facultativo en $2010,{ }^{67}$ seguido de Portugal e Italia. Al ser el Protocolo un instrumento tan reciente, existen pocos procesos de quejas individuales ante el Comité DESC. ${ }^{6}$ Sin embargo, resulta interesante observar que de los nueve casos ya resueltos por el Comité DESC a la fecha de redacción del presente artículo, ocho se refieren a España (y uno a Ecuador), ${ }^{69}$ y en uno de ellos el Comité concluyó que existió responsabilidad del Estado español por la falta de acceso efectivo a los tribunales para proteger el derecho a una vivienda adecuada. ${ }^{70}$ Para efecto de nuestro tema, valga observar que el caso contra Ecuador se refería al argumento de discriminación de un menor extranjero en la participación de torneos de fútbol de menores $;{ }^{71}$ sin embargo, el menor colombiano gozaba del estatuto de refugiado en Ecuador, esto es, era un migrante 'documentado' por lo que su situación no es directamente comparable a la del colectivo migrante. Aun así, la argumentación en materia de igualdad y no-discriminación exhibida en el caso sería extensible a la condición de las personas migrantes indocumentadas y como tal es un caso de valiosa consideración.

83. De los cuatro casos pendientes de resolución por el Comité DESC, dos de ellos se refieren a España (y los dos restantes a Ecuador). ${ }^{72}$ De modo que será interesante observar de cerca posibles procedimientos en relación con los DESC de las personas migrantes (indocumentadas) en los años por venir.

${ }^{67}$ España manifestó su consentimiento de ratificar el Protocolo Facultativo del PIDESC el 23 de septiembre de 2010; veáse BOE-A-2013-2081, del 25 de febrero de 2013.

${ }^{68}$ No obstante, cabe mencionare que sí existe una comunicación (distinto al procedimiento cuasi-judicial de queja individual) dirigida al actual Relator Especial de UN Sobre el Derecho Humano al Agua y al Saneamiento, por presuntas violaciones a los derechos humanos al agua potable y al saneamiento, entre otros, hacia alrededor de 435 personas de etnia gitana del asentamiento informal "El Gallinero" en Madrid; Comunicación del Relator de 9 de mayo de 2016 y respuesta del Gobierno de España de 19 de julio de 2016, disponibles en http://www.endwaterpoverty.org/blog/update-un-special-rapporteur-humanrights-water-and-sanitation

69 Véase 'Jurisprudencia del Comité DESC', en Oficina del Alto Comisionado de Naciones Unidas para los Derechos Humanos (OACNUDH), disponible en http://juris.ohchr.org/es/Search/Results.

70 Comité DESC de NU, IDG v España, E/C.12/55/D/2/2014, 13 de octubre de 2015. De los otros 7 casos contra España ya resueltos por el Comité, 6 de ellos fueron declarados inadmisibles -algunos de ellos por razones de forma (y no de fondo) o por la falta de agotamiento de recursos internos-, y en el caso restante (admitido) se determinó que no existió responsabilidad por parte del Estado.

${ }^{71}$ Comité DESC de NU, A.M.B. v Ecuador, E/C.12/58/D/3/2014, 8 de agosto de 2016.

72 Véase 'Resumen estadístico de las quejas individuales consideradas por el Comité de Derechos Económicos, Sociales y Culturales con arreglo al Protocolo Facultativo del Pacto Internacional de Derechos Económicos, Sociales y Culturales', Mayo de 2016, OACNUDH, en http://www.ohchr.org/EN/HRBodies/CESCR/Pages/PendingCases.aspx /, leído en conjunto con 'Jurisprudencia del Comité DESC', en Oficina del Alto Comisionado de Naciones Unidas para los Derechos Humanos (OACNUDH), disponible en http://juris.ohchr.org/es/Search/Results. 


\section{Riesgo y vulnerabilidad agravada para mujeres y niñas migrantes}

84. Las dificultades y violaciones diferenciadas y agravadas hacia las mujeres y niñas migrantes indocumentadas han sido ampliamente documentadas, ${ }^{73}$ incluidas aquellas que se derivan del complejo entramado normativo en el Estado español o de su puesta en práctica. ${ }^{74}$

85. Asimismo, el caso de las niñas y en general de los menores no acompañados (MENAs) ha sido denunciado como una de las situaciones de preocupación más intensa en materia de derechos humanos, entre otros instrumentos, a través de la Observación General No. 6 del Comité de Derechos del Niño, Trato de los menores no acompañados y separados fuera de su país de origen, adoptada por el Comité de NU de Derechos de la Niñez en 2005. Las violaciones que sufren los MENAs en el trayecto migratorio y a su llegada a las fronteras, así como las particulares condiciones de riesgo-agravadas en el caso de las niñas- por su presencia no acompañada de un adulto en el país receptor, comprendidas las relacionadas con la determinación de su edad, el abuso, la violencia de varios tipos incluso sexual, la detención, la privación de libertad, y el retorno forzado, han sido señaladas y analizadas en varios ámbitos. ${ }^{75}$

86. Nos referiremos aquí sólo a algunos de los supuestos generales más graves que afectan particularmente a mujeres y niñas en España y que encierran por ello una particular dimensión de género diferenciable de otro tipo de casos.

87. En relación con el derecho humano a la salud, aunque el efecto del RDL 16/2012, estudiado en el apartado anterior, pudiera verse revertido por el anuncio gubernamental de marzo de 2015 de rectificarlo parcialmente (en gran medida gracias a la campaña en este sentido de Médicos del Mundo), ${ }^{76}$ cabe hacer notar que el impacto de la eliminación de dicha atención en las personas inmigradas ha supuesto y sigue suponiendo consecuencias particularmente negativas para las mujeres en materia de violencia de género y de derechos sexuales y reproductivos. ${ }^{77}$

88. Ello debido a que varios estudios han comprobado que los servicios sanitarios, en especial la atención primaria, cumplen un papel fundamental a la hora de detectar mujeres en posibles situaciones

73 Véase, e.g., Relatora Especial de NU sobre Violencia contra las Mujeres, Informe presentado al Consejo de Derechos Humanos de NU, UNGA A/66/215, 2011; Human Rights Watch, “"The Law was Against Me”: Migrant Women's Access to Protection for Family Violence in Belgium', 2012; Amnistía Internacional, Informe sobre los Derechos Humanos en España, 2016; y D. EstradA-TANCK 'Undocumented Migrant Women in Europe: A Human Rights Perspective from Public International Law’, Croatian Yearbook of European Law and Policy, Vol. 12, 2016, pp. 119-143.

${ }^{74}$ Véase especialmente C. Ruzz SutiL, 'La técnica legal del "Hilo de Ariadna” en la protección internacional para la esclava de la trata', Cuadernos de Derecho Transnacional, Vol. 7, No 2, 2015, pp. 320-344; así como OrganizaCión InTERnaCional para las Migraciones (OIM)-Representación en España, 'Estudio sobre la Situación Laboral de la Mujer Inmigrante en España: análisis y proposiciones para la igualdad de trato y la lucha contra la discriminación', OIM, UE-Fondo Social Europeo, Gobierno de España-Ministerio de Empleo y Seguridad Social, España, 2015.

75 Representante Especial del Secretario General del Consejo de Europa sobre Personas Migrantes, Tomáš Boček, Informe temático sobre niñas y niños migrantes y refugiados, marzo de 2017; A. Bravo E I. Santos-GonzÁLEZ, 'Menores extranjeros no acompañados en España: necesidades y modelos de intervención', Psychosocial Intervention, Vol. 26, No. 1, 2013 , pp. 55-62; y denuncias articuladas en España por varias ONGs como Accem, Save the Children y Servicio Jesuita a Migrantes, véase S. MARQUÉs, 'Las dificultades de ser menor extranjero no acompañado (MENA) en España', Blog El Diario de la Educación, Fundación Periodismo Plural, 26 de enero de 2017, disponible en http://eldiariodelaeducacion.com/blog/2017/01/26/lasdificultades-de-ser-menor-extranjero-no-acompanado-mena-en-espana/; Defensor Del Pueblo, 'Los niños y los adolescentes en el informe anual del Defensor del Pueblo 2016', Madrid, 2017.

76 Véase Médicos DEl Mundo, "Cambiar algo para no cambiar nada", 31 de marzo de 2015, disponible en http://www. medicosdelmundo.org/index.php/mod.conts/mem.detalle_cn/relmenu.111/id.4272

77 Sobre este tema en España y en Europa en general, véase, e.g., D. Biswas, B. Toebes, A. HJern, H. Ascher y M. NorreDAM, 'Access to health care for undocumented migrants from a human rights perspective: A comparative study of Denmark, Sweden, and the Netherlands', Health and Human Rights Journal, Vol. 14, No. 2, 2013; M. SePúLVEDA, Relatora de NU sobre Extrema Pobreza y Derechos Humanos, 'Experta de la ONU pide a España "un auténtico compromiso con la protección de los derechos humanos para todos", OACNUDH, Ginebra, 29 de abril de 2014, disponible en http://www.ohchr.org/SP/NewsEvents/Pages/DisplayNews.aspx?NewsID=14545\&LangID=S\#sthash.ijCm0D5o.dpuf; y PICUM, 'Migrant Women's Health Issues: Addressing Barriers to Access to Health Care for Migrant Women with Irregular Status', Recomendación No. 85, 2016. 
de violencia, que además frecuentemente enfrentan barreras idiomáticas y culturales. Dado que como efecto del RDL 16/2012 las mujeres vieron "restringido su acceso regular a los servicios de atención primaria, la influencia de este hecho sobre la posibilidad de detectar casos de violencia de género se limita significativamente". ${ }^{78}$ Asimismo, el ejercicio de los derechos sexuales y reproductivos requiere un contexto en el que "todas las personas puedan decidir libremente sobre temas relacionados con su sexualidad y que, entre otras libertades, exista el acceso a información, educación y servicios de salud sexual y reproductiva, lo que el RDL 16/2012 imposibilita, especialmente, en el caso de las mujeres inmigradas en situación administrativa irregular". ${ }^{79}$

89. En este contexto, cabe enfatizar la labor que ha realizado el Comité de NU sobre los Trabajadores Migratorios y sus Familiares, antes estudiado, que ha adoptado una perspectiva sensible a las realidades diferenciadas que experimentan las personas migrantes con base en su género. En efecto, el Comité destaca respecto de las violaciones sufridas en el ámbito del trabajo doméstico, que "las trabajadoras domésticas migratorias se enfrentan además a otros riesgos por el hecho de ser mujeres, por ejemplo a la violencia de género". ${ }^{80}$ Asimismo, el Comité enfatiza ciertos riesgos particularizados sólo en el caso de las mujeres y el temor correlativo que agrava dichos peligros, cuando analiza a "las trabajadoras domésticas migrantes en situación irregular, que son especialmente vulnerables cuando quedan embarazadas, porque con frecuencia temen ser expulsadas del país si se dirigen a los servicios de salud pública". ${ }^{81}$

90. En la evaluación que realiza el Comité de NU de las obligaciones del Estado hacia las y los trabajadores domésticos migratorios indocumentados, especialmente las mujeres y los niños, dicho órgano califica las vulnerabilidades que enfrentan como 'extremas' y con base en el artículo 69 de la CTM llama a los Estados a que adopten medidas apropiadas para hacer frente a esas vulnerabilidades y a "considerar la posibilidad de adoptar políticas, como programas de regularización, para evitar que los trabajadores domésticos migratorios carezcan de documentación o corran el riesgo de encontrarse en situación irregular, o resolver tales situaciones". ${ }^{82}$

\section{Violaciones en frontera y 'devoluciones en caliente'}

91. En el ámbito de las violaciones a derechos humanos sufridas en la frontera, debe mencionarse el caso de Sonko v España, resuelto en 2012 por el Comité contra la Tortura de NU, órgano supervisor del cumplimiento de la Convención contra la Tortura. En este caso, el Comité revisó las condiciones de las personas migrantes indocumentadas de Senegal que tratan de llegar por barco a Ceuta, como el caso del Sr. Sonko que fue interceptado por la Guardia Civil en el mar y dejado cerca de la costa de Marruecos donde murió por ahogamiento, presuntamente por negligencia y actuar indebido de la policía de ese órgano. El Comité concluyó que existió responsabilidad del Estado español por haberse encontrado ejerciendo su jurisdicción y control efectivo sobre la persona desde el momento en que fue interceptada con vida y el momento en que murió de manera totalmente evitable. ${ }^{83}$

92. En el ámbito regional, debe ponerse el foco sobre la Decisión del TEDH de 30 de julio de 2015, en $N D$ y NT v España, referido a la admisibilidad del caso por la posible vulneración de derechos humanos respecto de las expulsiones automáticas, llamadas "devoluciones en caliente", de dos hombres subsaharianos de Mali y de Costa de Marfil que fueron sumaria y colectivamente expulsados del territo-

78 A. Morero Beltrán, y A. Ballesteros Peña, "Las consecuencias de la aplicación del Real Decreto-Ley de Regulación Sanitaria RD 16/2012 sobre la salud de las mujeres inmigradas", en Investigaciones feministas: papeles de estudios de mujeres, feministas y de género, $\mathrm{N}^{\circ} .5,2014$, p. 328.

79 Ibid., p. 330.

80 Comité de NU para la Protección de los Derechos de Todos los Trabajadores Migratorios y de sus Familiares, Observación General No. 1 sobre Trabajadores Migratorios Domésticos, CRMW/C/GC/1, 23 de febrero de 2011, párr. 7.

81 Ibid., párr. 43.

82 Comité CEDAW, Recomendación General No. 33, Acceso a la Justicia para las Mujeres, CEDAW/C/GC/33, 3 de agosto de 2015, párr. 49 .

${ }^{83}$ Comité de NU contra la Tortura, Sonko v España, CAT/C/47/D/368/2008, 27 de enero de 2012, en especial párr. 10.3. 
rio español por agentes policiales en la valla fronteriza de Melilla el 13 de agosto de 2014 con otros 75 individuos.$^{84}$ Dichas personas hasta ese momento eran migrantes indocumentados, pues como resultado de la expulsión ni siquiera se les permitió solicitar, en su caso, asilo en España. Con este caso se abre la posibilidad de que por primera vez el TEDH (y en general un tribunal internacional) se pronuncie sobre la legalidad internacional de este tipo de devoluciones por parte de la guardia civil en la frontera española-marroquí en las vallas de Ceuta y Melilla.

93. En este caso, el Tribunal no admitió a trámite parte de la demanda referida al artículo 3 (prohibición de tortura), en relación con la violencia a la que están expuestas las personas 'devolucionadas' hacia las fuerzas de seguridad marroquís. Por otro lado, sin embargo, el Tribunal admitió revisar más a fondo la alegación de que dichas devoluciones violan al artículo 4 del Protocolo 4 (prohibición de expulsiones colectivas) y el artículo 13 (derecho a un recurso efectivo) del CEDH.

94. Se estima que esta es una oportunidad para que el TEDH tome una postura no sólo sobre los casos individuales, sino de forma más amplia, acerca de la práctica sistemática de las devoluciones en caliente y los rechazos en frontera en España -misma que pretendió legalizarse mediante la Ley de Seguridad Ciudadana adoptada en $2015,{ }^{85}$ pero que es contraria a la Constitución española, el Derecho Internacional de los Derechos Humanos y el Derecho Internacional de Refugiados. ${ }^{86}$ Será interesante observar también si en su análisis de fondo, el Tribunal toma en cuenta los Principios y Directrices Recomendados sobre los Derechos Humanos en las Fronteras Internacionales de la OACNUDH, adoptados en 2014, y antes revisados.

95. Aunque el caso de $N D$ y $N T$ v España se encuentra pendiente de resolución al momento de redacción del presente texto, baste por ahora señalar que la posición de los demandantes en el caso se vio respaldada por dictámenes jurídicos del Consejo de Derechos Humanos de Naciones Unidas, del Alto Comisionado de las Naciones Unidas para los Refugiados (ACNUR), del Comisario de Derechos Humanos del Consejo de Europa, de Amnistía Internacional y de la Comisión Española de Ayuda al Refugiado.

96. Precisamente a raíz de este caso contra España ante el TEDH, la Oficina del Alto Comisionado de NU para los Derechos Humanos ha resaltado que el derecho internacional de los derechos humanos impone ciertas limitaciones al poder soberano de un Estado de remover a los migrantes de su territorio. Específicamente, limita su capacidad de expulsarlos cuando se encuentren en riesgo de enfrentar un grave daño al regreso a su país de origen. Los Estados tienen la responsabilidad de ejercitar la debida diligencia y no perpetuar las violaciones de derechos humanos y los abusos por vía de retornar a

84 TEDH, ND y NT v España, $\mathrm{N}^{\circ}$ 8675/15 y 8697/15, Decisión de admisibilidad, 30 de julio de 2015. Para un análisis detallado, véase R. Naranjo Sandalio, 'Spain's Summary Returns to Morocco: A Case Pending Before the European Court of Human Rights', Blog Forced Migration Forum, 14 de febrero de 2017, disponible en https://forcedmigrationforum. com/2017/02/14/spains-summary-returns-to-morocco/

${ }^{85}$ Ley Orgánica 4/2015, de 30 de marzo, de Protección de la Seguridad Ciudadana, BOE núm. 77, de 31 de marzo de 2015, "Disposición final primera. Régimen especial de Ceuta y Melilla. 1. Se adiciona una disposición adicional décima a la Ley Orgánica 4/2000, de 11 de enero, sobre derechos y libertades de los extranjeros en España y su integración social, con la siguiente redacción: «Disposición adicional décima. Régimen especial de Ceuta y Melilla. 1. Los extranjeros que sean detectados en la línea fronteriza de la demarcación territorial de Ceuta o Melilla mientras intentan superar los elementos de contención fronterizos para cruzar irregularmente la frontera podrán ser rechazados a fin de impedir su entrada ilegal en España. 2. En todo caso, el rechazo se realizará respetando la normativa internacional de derechos humanos y de protección internacional de la que España es parte..."

86 Véase, e.g. J.V. GonzÁlez García, 'Expulsiones "en caliente", devoluciones y petición de asilo en Ceuta y Melilla', Revista de administración pública, No 196, 2015, pp. 309-329; E. SAGARRA Trias, 'La discutible constitucionalidad de la regulación de las devoluciones en caliente (I)', Abogacía Española, 15 de abril de 2015, disponible en http://www.abogacia. es/2015/04/15/la-discutible-constitucionalidad-de-la-regulacion-de-las-devoluciones-en-caliente-i/; COMITÉ DE DERECHOS HUMANOS DE NU, 'Observaciones finales sobre el sexto informe periódico de España', CCPR/C/ESP/CO/6, 14 de agosto de 2015, párr. 18; y M. Martínez Escamilla, “"Devoluciones en caliente”. Un análisis jurídico', Derechos humanos y justicia universal en la frontera sur, Coord. por José Luis Villena Higueras, 2016, pp. 77-96. 
las personas migrantes a una situación de daño, o a exacerbar sus vulnerabilidades y riesgos particulares a través de sus acciones u omisiones. ${ }^{87}$

\section{Reflexiones finales}

97. La situación de los derechos humanos de las personas migrantes indocumentadas en España presenta diversas ambivalencias.

98. Por un lado, España es Estado Parte de todos los principales instrumentos internacionales de derechos humanos en el sistema de NU que expresamente reconocen esos derechos a todas las personas y protegen a las personas migrantes indocumentadas bajo los principios de igualdad y no-discriminación. España se encuentra, por tanto, jurídicamente vinculado por dichos tratados, además de estar obligado al general cumplimiento del derecho internacional de los derechos humanos. Por otro lado, se excluye, junto con el resto de Estados Miembros de la UE, de la Convención Internacional para la Protección de los Derechos de Todos los Trabajadores Migratorios y sus Familiares, aspecto que apuntaría hacia una falta de compromiso integral con los derechos humanos de las personas migrantes.

99. A nivel regional, a pesar de existir un marco jurídico de derechos humanos, sobre todo en el ámbito del Consejo de Europa, existen retos prácticos al momento de la implementación, y también disposiciones contrarias a los derechos humanos en el propio Derecho de la UE, como el caso de la Directiva de Retorno de 2008. Si bien es cierto que todo sistema jurídico tiene sus antinomias y contradicciones, puede decirse que el Derecho de la UE ha inclinado la balanza por la cohesión regional de la propia Unión desfavoreciendo indirectamente y en ocasiones abiertamente vulnerando los derechos humanos de las personas migrantes indocumentadas.

100. Como se ha visto, esa especie de 'esquizofrenia normativa' se reproduce también a nivel del derecho positivo en España, en ocasiones retroalimentado y fundamentado por las posturas y exigencias jurídicas de la UE.

101. Por su parte, los mecanismos de protección de los derechos humanos, tanto a nivel de NU como a nivel europeo principalmente a través del TEDH, han admitido o resuelto varios casos contra España, revelando con ello que aún falta mucho por hacer para lograr el pleno reconocimiento de la igual dignidad de las personas migrantes indocumentadas, cuya condición de estatus migratorio irregular los coloca en situación de discriminación y de vulnerabilidad, particularmente agravada en el caso de mujeres, niñas y niños.

102. A la vez, algunas de estas fuentes interpretativas abren caminos esperanzadores a través de sus posturas progresistas y expansivas del alcance de los derechos, a modo de dejar entrar a las personas migrantes indocumentadas -jurídica y literalmente- en el territorio del pleno goce de su dignidad con base en la promesa original de la Declaración Universal de los Derechos Humanos de 1948 y como piedra de toque de todas las sociedades democráticas.

87 OACNUDH, Intervener Brief filed by the United Nations High Commissioner for Human Rights, pursuant to leave granted by the Court on 9 October 2015', en el caso del TEDH, N.D. y N.T. v España, op. cit., párr. 2 (traducción propia). 